\title{
An experimental and kinetic modeling study of the oxidation of hexane isomers: Developing consistent reaction rate rules for alkanes
}

\author{
Kuiwen Zhang ${ }^{1 *}$, Colin Banyon ${ }^{2}$, Ultan Burke ${ }^{2}$, Goutham Kukkadapu ${ }^{1}$, Scott W. Wagnon ${ }^{1}$, \\ Marco Mehl ${ }^{3}$, Henry J. Curran², Charles K. Westbrook ${ }^{1}$, William J. Pitz ${ }^{1}$ \\ ${ }^{1}$ Lawrence Livermore National Laboratory, Livermore, CA, USA \\ ${ }^{2}$ Combustion Chemistry Centre, School of Chemistry, Ryan Institute, MaREI, \\ National University of Ireland Galway, Galway, Ireland \\ ${ }^{3}$ Politecnico di Milano, Piazza Leonardo da Vinci 32, 20133 Milano, Italy
}

\begin{abstract}
Alkanes are key components in gasoline, jet and diesel fuels and considerably influence the combustion behavior of these fuels because of their wide range of reactivity. An improved understanding of their combustion behavior and the development of chemical kinetic models that can accurately simulate their combustion behavior are important for the development of nextgeneration internal-combustion and gas-turbine engines. The current work provides improved insight into oxidation mechanisms of a representative family of hydrocarbon fuels, specifically the hexane isomers: n-hexane, 2-methylpentane, 3-methylpentane, 2,2-dimethylbutane and 2,3dimethylbutane. These isomers provide carbon "skeletons" ranging from straight-chained to highly-branched and provide a framework for the subsequent development of kinetic mechanisms for larger alkanes. New ignition delay times for the four branched hexane isomers were measured
\end{abstract}

\footnotetext{
* Corresponding author E-mail: kuiwen.zhang@convergecfd.com, present address: Convergent Science, 6400 Enterprise Ln, Madison, WI 53719, USA
} 
in a high-pressure shock tube and in a rapid compression machine, both at stoichiometric conditions ( $\varphi=1), p=15$ bar and $X_{\mathrm{O} 2}=21 \%$ over temperatures from 600 to1300 K. These data were combined with previously published measurements under the same conditions for the remaining $n$-hexane isomer to provide a complete body of experimental data for kinetic modeling analysis. In addition, very recent experimental measurements of individual intermediate chemical species concentrations from all five hexane isomers in a jet-stirred reactor are also included and provide another family of data for further assessment of hexane isomer reactivity. Different reactivities were observed for each hexane isomer in each experimental facility, resulting from differences in their molecular structures. Consistent reaction rate rules have been applied to develop a combined detailed chemical kinetic model for all five hexane isomers. Kinetic model validation studies are reported to show that the current model reproduces well the ignition delay times of all five alkane isomers, as well as their variations in reactivity over a wide range of temperatures and other operating conditions. Equally important, these results show that it is not necessary to have a separate, different kinetic model for each isomer of a family of alkane fuels and that a single, coherent, integrated set of reaction rate classes and rules is sufficient to accurately describe combustion rates of combustion of straight-chain $n$-alkanes and branched-chain alkane fuels. This suggests strongly that a single set of reaction classes and rate rules should be sufficient to describe combustion kinetics of alkane fuels of any size and degree of branching.

\section{Keywords}

Hexane isomers, detailed kinetic model, ignition delay time, reaction rate rules, rapid compression machine. 


\section{Introduction}

The development of low-emission, high-efficiency engines and advanced combustion strategies [1] requires reliable kinetic models to describe fuel combustion properties, which stem from the molecular structure of the fuel. Therefore, it is interesting to systematically investigate a group of fuel isomers to explore the influence of fuel molecular structure upon fuel reactivity, independent of fuel molecule size. For example, auto-ignition of the butane isomers was studied in a rapid compression machine (RCM) by Healy et al. [2, 3], showing how and why iso-butane is less reactive than $n$-butane. Investigation of the pentane isomers by Ribaucour et al. [4] and more recently by Bugler et al. [5], concluded that, in the RCM at temperatures below 900K, $n$-pentane is the most reactive of the three isomers, while iso-pentane is the least reactive and the rate of neopentane ignition lies between the other two isomers. However, at temperatures above about 900K, ignition rates of all three pentane isomers were found to very nearly equal. Wang et al. [6] studied the oxidation of all five hexane isomers in a Jet-Stirred Reactor (JSR), at atmospheric pressure, stoichiometric conditions, and temperatures from 550 to $1000 \mathrm{~K}$, using both gas chromatography and synchrotron vacuum ultraviolet photoionization mass spectrometry [7] at low and intermediate temperatures. Wang et al. observed that fuel reactivity at low and intermediate temperature decreases when there are more methyl side-branches in the fuel molecule. Similar conclusions were reached by Silke et al. [8] who measured ignition delay times (IDTs) for all nine heptane isomers in a rapid compression machine. Zhang et al. $[9,10]$ used a common modeling approach to study both $n$-hexane and $n$-heptane fuels in a variety of different experimental facilities, and their kinetic mechanism forms the foundation of the present kinetic modeling study of the hexane 
isomers. Westbrook et al. [11,12] developed kinetic mechanisms for the heptane isomers and validated them for a variety of test environments and a wide range of reaction temperatures and pressures. Smith et al. [13] measured ignition delay times of 4 different isomers of heptane in a shock tube at temperatures from 1150 to $1650 \mathrm{~K}$ and reflected shock pressure of $2 \mathrm{~atm}$ and found that the high temperature ignition delay times of all four heptane isomers were essentially the same, in agreement with kinetic predictions of Westbrook et al. [12] and Curran et al. [14].

The present hexane isomer mechanism provides consistent rate rules for $n$-alkanes, as well as other studies to provide rate rules for branched alkane fuels as large as iso-octane, iso-dodecane, and iso-cetane [15-22]. In their kinetic modeling study of the pentane isomers, Bugler et al. [5] suggested that their pentane isomers mechanism might provide a template for kinetic modeling of larger alkanes, and the present set of reaction rate rules add to that concept and could form a basis for reaction rate rules for many straight-chain and branched alkanes of $\mathrm{C}_{7}$ chain length and even larger. In fact, the same or very similar set of reaction rate rules have been used very recently to simulate the high temperature ignition of branched-chain isomers of nonane, dodecane, and hexadecane [15]. The present work can be regarded as a further step using both experimental measurements and kinetic modeling towards providing a better explanation for the correlation of fuel molecule structure and reactivity from a chemical kinetic perspective.

In this study, new ignition delay times were measured for the four branched hexane isomers, 2-methylpentane (2MP), 3-methylpentane (3MP), 2,2-dimethylbutane (22DMB) and 2,3dimethylbutane (23DMB) in a high-pressure shock tube (HPST) and in a rapid compression machine (RCM) at stoichiometric conditions and pressure of 15 bar over the temperature range of 
600-1300 K. These data were combined with previously published results for $n$-hexane (NHX) that had been measured under the same conditions [9]. Recently published experimental values of intermediate chemical species mole fractions obtained in a Jet-Stirred Reactor [6] with the same hexane isomers were also included in the experimental literature used to develop and evaluate the chemical kinetic reaction mechanism for the hexane isomers, the simplified chemical structures of which are:

$\begin{array}{lc}\text { n-hexane } & \mathrm{C}-\mathrm{C}-\mathrm{C}-\mathrm{C}-\mathrm{C}-\mathrm{C} \\ \text { 2-methyl pentane } & \mathrm{C}-\mathrm{C}-\mathrm{C}-\mathrm{C}-\mathrm{C} \\ \text { 3-methyl pentane } & \mathrm{C}-\mathrm{C}-\mathrm{C}-\mathrm{C}-\mathrm{C} \\ & \mathrm{C} \\ \text { 2,2-dimethyl butane } & \mathrm{C}-\mathrm{C}-\mathrm{C}-\mathrm{C} \\ \text { 2,3-dimethyl butane } & \mathrm{C} \\ & \mathrm{C}-\mathrm{C}-\mathrm{C}-\mathrm{C} \\ & \mathrm{C} C\end{array}$

A detailed kinetic model was assembled and used to simulate each of the available experiments from the RCM, HPST, and JSR, consisting of ignition delay times (IDTs) for the RCM and shock tube experiments and temperature-dependent chemical species mole fractions from the JSR experiments. Different reactivities were observed for each of the hexane isomers in each of the experiments, and these experimental results were compared with kinetic modeling results. Sensitivity and rate of production analysis were used to identify the key reaction pathways that control the combustion of all five hexane isomers. 


\section{Experiment}

\subsection{Rapid Compression Machine}

The RCM at UCI Galway used here was described previously [9]. In brief, the machine has a twin, opposed-piston configuration. The machine is equipped with an external heating system allowing it to operate at a variety of initial temperatures for a fixed geometric compression ratio. The change in pressure from its initial to its compressed value is measured using a Kistler 601A pressure. The IDT is quantified as the time between the first local maximum on the pressure-time history (end of compression) to the global maximum in pressure rise rate as shown in Fig. 1(a). In the case shown in Fig. 1(a), where two-stage ignition is observed in the RCM, the first-stage ignition time is quantified as the time to its first locally maximum pressure rise rate following the end of the compression stroke. To quantify facility effects for simulations, all reactive conditions investigated are accompanied by concurrent non-reactive experiments, where the oxygen mole fraction is replaced with the nitrogen, which has a similar heat capacity to that of oxygen. Experiments were usually performed in triplicate or at a minimum in duplicate.

\subsection{High Pressure Shock Tube}

Similar to the RCM, the HPST has also been described in detail previously [9]. Briefly, it is comprised of a $3.0 \mathrm{~m}$ driver section and a $5.73 \mathrm{~m}$ driven section. These are separated by two prescored aluminum diaphragms, on which the scoring depth can be varied depending on the intended target bursting pressure. There are six axially positioned PCB113B24 pressure transducers mounted in the walls of the tube. The IDT is measured using a Kistler 603B pressure transducer 
mounted in the endwall of the tube.

The tube is equipped with an external heating system which allows for operation at different initial temperatures. All of the fuels, NHX (96\%), 2MP (98\%), 3MP (99\%), 22DMB (97\%) and 23DMB (99\%) were supplied by TCI UK and were used without further purification. Nitrogen (> 99.96\%), oxygen (> 99.5\%), argon (> 99.5\%) and carbon dioxide (> 99.5\%) gases were supplied by BOC Ireland. Mixtures were prepared manometrically and allowed to mix via gaseous diffusion for at least 12 hours before performing experiments. The rate of preignition pressure increase observed in the shock tube was below $1 \% \mathrm{~ms}^{-1}$, as shown in Fig. 1(b). The uncertainty in the measured IDTs is estimated to be $15 \%$ in both the HPST and in the RCM. The shock tube and RCM experimental data are provided in tabular format as Supplementary data.
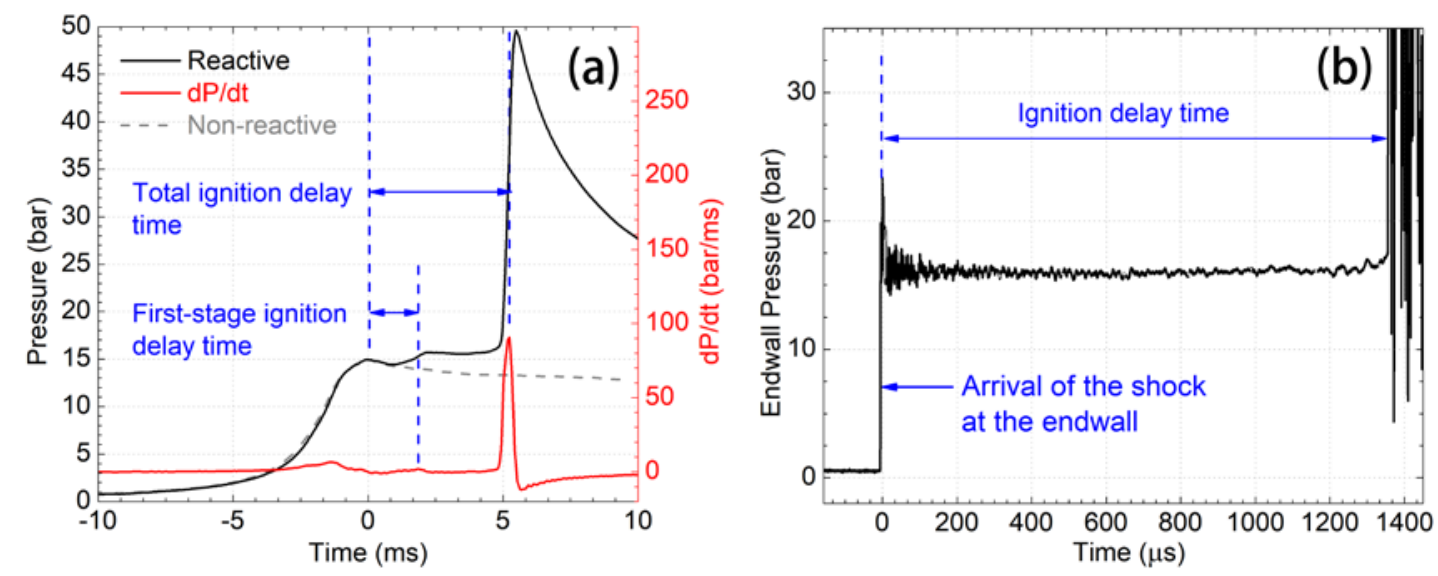

Fig. 1. (a) Example RCM pressure trace for 2-methylpentane in air at $T_{\mathrm{C}}=733 \mathrm{~K}, \varphi=1.0$ in air; (b) Example HPST endwall pressure trace for 3-methylpentane in air at $T_{5}=1045 \mathrm{~K}, \varphi=1.0$ in air. 


\section{Kinetic Modeling}

The kinetic model developed in this work for the hexane isomers is based on that proposed by Westbrook et al. [11,12] for the oxidation of the nine heptane isomers and later updated by Sarathy et al. [21], who developed kinetic mechanisms for the 2-methyl alkanes from $\mathrm{C}_{7}$ to $\mathrm{C}_{20}$, using reaction classes consistent with those proposed previously. AramcoMech 2.0 [23] was adopted as the base mechanism for the $\mathrm{C}_{0}-\mathrm{C}_{4}$ species, while the sub-mechanisms for pentane isomers were taken from the work by Bugler et al. [5]. The thermodynamic data have been estimated using the THERM [24] code based on the group additivity method proposed by Benson [25] using updated group values [26, 27].

For the high-temperature chemistry, reaction rates have been updated to retain consistency with other sub-models $[5,10]$. Reaction rates for $\mathrm{H}$-atom abstraction by $\mathrm{OH}$ radicals were adopted from the work of Sivaramakrishnan et al. [28]. For H-atom abstraction reactions from the fuel by other radicals and atoms, reaction rates have been updated according to analogous reactions in the pentane isomers [5]. For $\mathrm{H}$-atom abstraction by $\mathrm{HO}_{2}$ radicals from secondary carbon atoms, the Afactor has been multiplied by 1.5 to improve the model performance at intermediate temperatures, which is within the uncertainty range estimated in [21].

Low-temperature reactivity of alkane fuels is dominated by competition between chain branching and chain propagating reaction pathways, which originate with the addition of fuel radicals to molecular oxygen $\mathrm{O}_{2}$ [29]; the adduct alkyl peroxyl radicals $\left(\mathrm{RO}_{2}\right)$ then undergo internal isomerization [30] to produce hydroperoxyl alkyl radicals (QOOH), which then add to oxygen [5, 
$9,10,29]$ to make peroxy-hydroperoxy alkyl radicals $\left(\dot{\mathrm{O}}_{2} \mathrm{QOOH}\right)$. This can be followed by an isomerization reaction of the $\dot{\mathrm{O}}_{2} \mathrm{QOOH}$ to produce carbonyl-hydroperoxide species [30], eventually producing chain branching by producing two $\dot{\mathrm{OH}}$ radicals from the initial fuel radical.

Chain propagation results primarily from concerted $\mathrm{HO}_{2}$ radical elimination reactions from alkyl peroxyl radicals and peroxy-hydroperoxylalkyl radicals [31], as well as the formation of cyclic ethers from hydroperoxyl alkyl radicals [32]. However, the formation of hydroperoxyl cyclic ethers [32] is chain branching rather than chain propagating, as both the formation and decomposition of hydroperoxyl cyclic ethers produce $\dot{\mathrm{OH}}$ radicals. The $\beta$-scission of hydroperoxyl alkyl radicals into a carbonyl species, alkene and ȮH radical [32] is a minor reaction class that contributes to chain propagation, while the decomposition of di-hydroperoxyl alkyl radicals may contribute to either chain propagation or chain branching depending on whether or not the decomposition produces an $\dot{\mathrm{OH}}$ radical from each of the hydroperoxyl groups. Recently, an alternative pathway for further isomerization of the $\dot{\mathrm{O}}_{2} \mathrm{QOOH}$ radicals has been recognized $[16,33,34]$ that leads to a variety of chain branching and chain propagation reaction steps that contribute relatively small modifications to the overall reactivity of these fuels. All of these low temperature reaction pathways are quite complex, with reaction rates that vary with molecular structure, especially with the size of the transition state ring structures involved in the $\mathrm{H}$ atom transfers within the reacting radical species. The key result of all of these reactions is the overall ratio of chain branching to chain propagation that the entire family of low temperature reactions produces. While the $\mathrm{C}_{5}$ alkane isomers exhibit much of this low temperature kinetics, the full complexity is achieved for the $\mathrm{C}_{6}$ and larger alkane isomers, so hexane fuels represent the first 
opportunity to examine the entire family of low temperature kinetic reaction pathways and therefore present an ideal starting point for continued extensions of these phenomena to larger alkane fuel systems.

The reaction rules for the formation of cyclic ethers in this work are taken from Villano et al. [32], which are based on the heats of reaction for cyclic ether formation at $298 \mathrm{~K}\left(\Delta H_{\mathrm{rxn}} @ 298 \mathrm{~K}\right)$. However, Villano et al. provided two different recommendations for the rates of these cyclic ether formation reactions, one consisting of an extensive list of theory computations using transition state theory to calculate the CBS-QB3 barrier heights for each of the isomerization reactions, with a second calculation based on relatively simple group additivity principles. The $\Delta H_{\mathrm{rxn}} @ 298 \mathrm{~K}$ estimated using group additivity is lower than that calculated by Villano et al. [32] by about 2.2 $\mathrm{kcal} \mathrm{mol}^{-1}$ on average for the formation of 3-membered and 4- membered ring cyclic ethers. Therefore, we have adjusted the activation energies by adding $2.2 \mathrm{kcal} \mathrm{mol}^{-1}$ to $\Delta H_{r x n} @ 298 \mathrm{~K}$ to the linear correlation proposed by Villano et al. for the formation of 3- and 4-membered ring cyclic ethers, so the reaction rates generated using the modified reaction rate rules agree better with the specific rates calculated by Villano et al., and are more suitable to act as a basis for further optimizations.

We have used reaction rate rules proposed by Sharma et al. [30] for the particularly important chain-branching reactions that produce carbonyl-hydroperoxides. However, Sharma et al. primarily emphasized reactions no larger than pentanes and reported rates for only a small number of larger QOOH and $\dot{\mathrm{O}}_{2} \mathrm{QOOH}$ radicals, so rates of some of these reactions required for the larger hexane fuels have been estimated from analogous reactions. At the present time, we do not include 
reactions in the kinetic mechanisms that involve a cyclic transition state ring larger than seven total $\mathrm{C}, \mathrm{O}$, and $\mathrm{H}$ atoms, so little further estimation of such rates beyond those in the work of Sharma et al. is likely to be needed when extending mechanisms to larger fuel molecules. Similar size limitations of transition state ring structure isomerization reactions for other low temperature isomerization reactions used in these calculations were found and the rates were estimated in the same way. For $\gamma$ - $\dot{\mathrm{O}}_{2} \mathrm{QOOH}$ radicals with a secondary carbon-bearing hydroperoxyl group and a tertiary carbon-bearing peroxyl group, the reaction rate is taken from that of $\gamma$ - $\dot{\mathrm{O}}_{2} \mathrm{QOOH}$ radicals with secondary carbon atoms bearing both hydroperoxyl and peroxyl groups, with the A-factor multiplied by 1.5 and Ea reduced by $1 \mathrm{kcal} \mathrm{mol}^{-1}$. Activation energies for the decomposition of ketohydroperoxides are reduced by $0.5 \mathrm{kcal} \mathrm{mol}^{-1}$ compared to those of $n$-hexane and $n$-heptane $[9,10]$ for better predictions of low temperature reactivities of all hexane isomers.

Some minor tunings on the reaction rate rules from Villano et al. [31,32] were applied to improve the model performance, with the details shown in Table 1. In general, some reaction rate A-factors are multiplied by a factor of $0.5 \sim 2$ to change their reaction rates at all temperatures, and some activation energies are incremented by $\pm 1 \mathrm{kcal} \mathrm{mol}^{-1}$ to change the temperature dependence of the reaction rate. These tunings are recommended for the present hexane models and as a starting point for the development of models for larger alkanes. A table with the complete reaction rate constants used is given in the supplemental data. All of the tunings are within the uncertainty ranges reported in the corresponding literature from which the relevant rate constants were originally reported. 
Some reaction rate rules proposed in the literature are based on an average of rate constants for a series of analogous reactions. For example, Villano et al. [31,32] specified reaction rate fits for specific reactions, and averaged reaction rate rules for a larger body of analogous reactions. The latter average rate rules often have higher uncertainties because of the effect of alkyl substitutions in a series of analogous reactions. In addition, a detailed kinetic model consists of hundreds of reaction rates that have been derived by different researchers using various methods. Therefore, tunings of the reaction rate rules within the reported uncertainty ranges in this work are necessary and reasonable. Future extensions of the present models to larger alkane fuels may enable some reduction in these uncertainties. The kinetic mechanism, thermodynamic data, transport data, and species dictionary are all available as Supplementary material. 
Table 1. Recommended tunings of the reaction rate rules from Villano et al. [31,32] for use in the hexane model.

\begin{tabular}{|c|c|c|c|c|c|c|}
\hline Reaction class & \multicolumn{3}{|c|}{ Reactant structure } & \multicolumn{2}{|c|}{ Tuning } & Note \\
\hline \multirow{7}{*}{$\begin{array}{l}\text { Concerted } \\
\qquad \mathrm{HO}_{2} \\
\text { elimination } \\
{[31]}\end{array}$} & \multicolumn{2}{|c|}{$\mathrm{OO}$ site } & H site & $A x$ & $\mathrm{Ea}+$ & Example \\
\hline & \multicolumn{2}{|c|}{$\mathrm{P}$} & $\mathrm{s}$ & 1.5 & 0 & $\mathrm{CC}(\mathrm{C}) \mathrm{CCCOO} . \rightarrow \mathrm{CC}(\mathrm{C}) \mathrm{CC}=\mathrm{C}+\mathrm{HO} 2$ \\
\hline & \multicolumn{2}{|c|}{$\mathrm{P}$} & $\mathrm{T}$ & 2 & -1000 & $\mathrm{CC}(\mathrm{COO}.) \mathrm{CCC} \rightarrow \mathrm{CC}(=\mathrm{C}) \mathrm{CCC}+\mathrm{HO} 2$ \\
\hline & \multicolumn{2}{|c|}{$\mathrm{S}$} & $\mathrm{P}$ & 1.5 & 500 & $\mathrm{CC}(\mathrm{C}) \mathrm{CC}(\mathrm{OO}.) \mathrm{C} \rightarrow \mathrm{CC}(\mathrm{C}) \mathrm{CC}=\mathrm{C}+\mathrm{HO} 2$ \\
\hline & \multicolumn{2}{|c|}{$\mathrm{S}$} & $\mathrm{s}$ & 1.2 & 0 & $\mathrm{CC}(\mathrm{C}) \mathrm{CC}(\mathrm{OO}.) \mathrm{C} \rightarrow \mathrm{CC}(\mathrm{C}) \mathrm{C}=\mathrm{CC}+\mathrm{HO} 2$ \\
\hline & \multicolumn{2}{|c|}{$\mathrm{S}$} & $\mathrm{T}$ & 2 & 0 & $\mathrm{CC}(\mathrm{C}) \mathrm{C}(\mathrm{OO}.) \mathrm{CC} \rightarrow \mathrm{CC}(\mathrm{C})=\mathrm{CCC}+\mathrm{HO} 2$ \\
\hline & \multicolumn{2}{|c|}{$\mathrm{T}$} & $\mathrm{T}$ & 2 & -1000 & $\mathrm{CC}(\mathrm{C})(\mathrm{OO}.) \mathrm{C}(\mathrm{C}) \mathrm{C} \rightarrow \mathrm{CC}(\mathrm{C})=\mathrm{C}(\mathrm{C}) \mathrm{C}+\mathrm{HO} 2$ \\
\hline \multirow{12}{*}{$\begin{array}{l}\text { Cyclic ether } \\
\text { formation [32] }\end{array}$} & $\mathrm{OOH}$ site & Carbon atoms in ring & Radical site & $A x$ & $\mathrm{Ea}+$ & Example \\
\hline & $\mathrm{S}$ & 2 & $\mathrm{~S}$ & 0.5 & 2000 & $\mathrm{CC} . \mathrm{CCCC} \rightarrow \mathrm{CC} 1 \mathrm{C}(\mathrm{O} 1) \mathrm{CCC}+\mathrm{OH}$ \\
\hline & $\mathrm{T}$ & 2 & $\mathrm{P}$ & 2 & -1000 & $\mathrm{C.C}(\mathrm{C})(\mathrm{OOH}) \mathrm{CCC} \rightarrow \mathrm{C} 1 \mathrm{C}(\mathrm{C})(\mathrm{O} 1) \mathrm{CCC}+\mathrm{OH}$ \\
\hline & $\mathrm{P}$ & 3 & $\mathrm{~s}$ & 1.5 & 0 & $\mathrm{CC}(\mathrm{C}) \mathrm{C} . \mathrm{CCOOH} \rightarrow \mathrm{CC}(\mathrm{C}) \mathrm{C} 1 \mathrm{CCO} 1+\mathrm{OH}$ \\
\hline & $\mathrm{P}$ & 3 & $\mathrm{~T}$ & 2 & 0 & $\mathrm{CCC} .(\mathrm{C}) \mathrm{CCOOH} \rightarrow \mathrm{CCC} 1(\mathrm{C}) \mathrm{CCO} 1+\mathrm{OH}$ \\
\hline & $\mathrm{S}$ & 3 & $\mathrm{~S}$ & 1 & 1000 & $\mathrm{CC}(\mathrm{OOH}) \mathrm{CC} . \mathrm{CC} \rightarrow \mathrm{CC}(\mathrm{O} 1) \mathrm{CC} 1 \mathrm{CC}+\mathrm{OH}$ \\
\hline & $\mathrm{S}$ & 3 & $\mathrm{~T}$ & 2 & 0 & $\mathrm{CC} .(\mathrm{C}) \mathrm{CC}(\mathrm{OOH}) \mathrm{C} \rightarrow \mathrm{CC} 1(\mathrm{C}) \mathrm{CC}(\mathrm{O} 1) \mathrm{C}+\mathrm{OH}$ \\
\hline & $\mathrm{P}$ & 4 & $\mathrm{P}$ & 1 & -1000 & C.C(C)C(C)COOH $\rightarrow \mathrm{C} 1 \mathrm{C}(\mathrm{C}) \mathrm{C}(\mathrm{C}) \mathrm{CO} 1+\mathrm{OH}$ \\
\hline & $\mathrm{P}$ & 4 & $\mathrm{~S}$ & 0.5 & 0 & $\mathrm{CCC} . \mathrm{CCCOOH} \rightarrow \mathrm{CCC} 1 \mathrm{CCCO} 1+\mathrm{OH}$ \\
\hline & $\mathrm{P}$ & 4 & $\mathrm{~T}$ & 1 & 1000 & $\mathrm{CC} .(\mathrm{C}) \mathrm{CCCOOH} \rightarrow \mathrm{CC} 1(\mathrm{C}) \mathrm{CCCO} 1+\mathrm{OH}$ \\
\hline & $\mathrm{s}$ & 4 & $\mathrm{P}$ & 0.5 & 0 & $\mathrm{CCC}(\mathrm{OOH}) \mathrm{CCC} . \rightarrow \mathrm{CCC} 1 \mathrm{CCCO} 1+\mathrm{OH}$ \\
\hline & $\mathrm{S}$ & 4 & $\mathrm{~s}$ & 0.5 & 1000 & $\mathrm{CC}(\mathrm{OOH}) \mathrm{CCC} . \mathrm{C} \rightarrow \mathrm{CC} 1 \mathrm{CCC}(\mathrm{O} 1) \mathrm{C}+\mathrm{OH}$ \\
\hline
\end{tabular}

\section{Results and discussion}

Simulations were performed using the Chemkin-Pro [35] software. In simulating the HPST data, constant volume conditions were assumed because the IDTs are below approximately $1.0 \mathrm{~ms}$, thereby limiting the possibility of local facility effects, and the Stirred Reactor option was used to simulate the JSR experiments from Wang et al. [6].

Ignition Delay Times in RCM and Shock Tube Experiments

The RCM simulations used non-reactive volume histories to take facility effects into consideration [36], mainly due to heat transfer to the walls of the RCM chamber or premature 
chemical heat release. The non-reactive volume histories measured in this work are available as Supplementary material. The end-of-compression pressures in the non-reactive and reactive pressure histories were compared to check for reaction during compression and no such reaction was observed. For all RCM simulations, the ignition events (first- and second-stage ignition) are defined by "steps" in the pressure rise rate after reaching the end-of-compression pressure, as illustrated in Fig. 1(a).
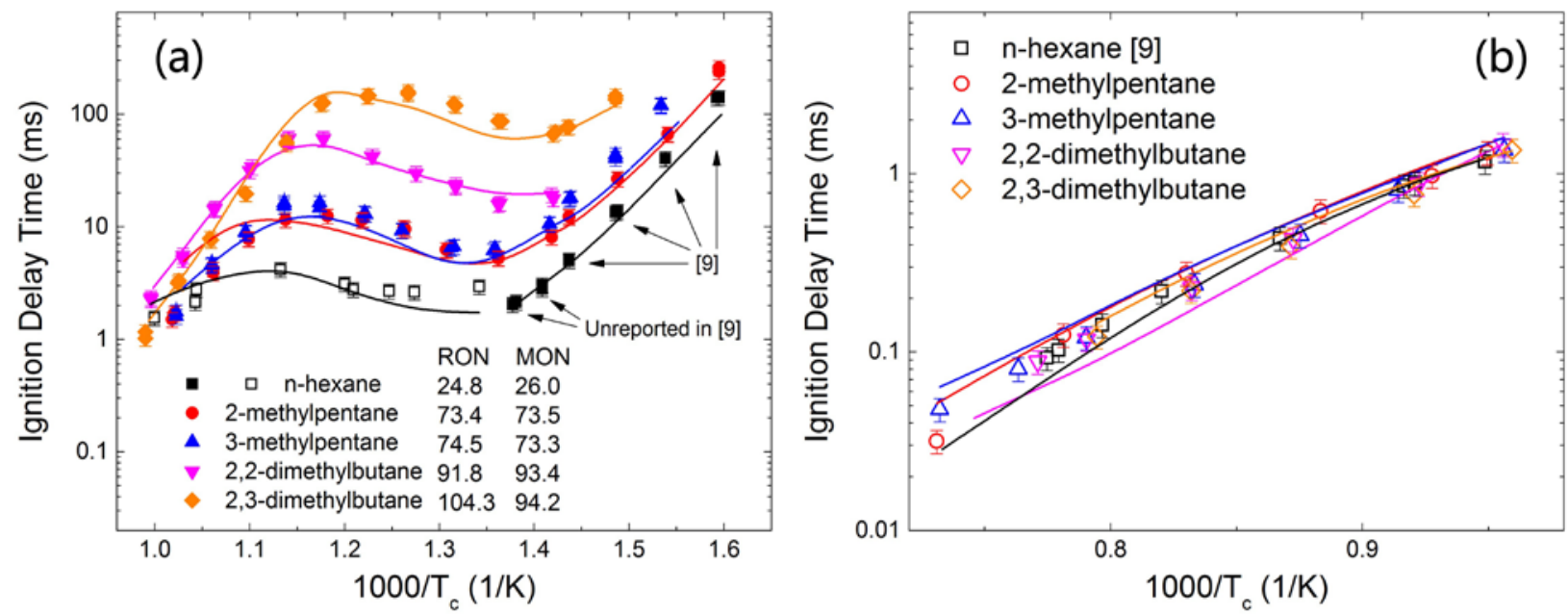

Fig. 2. Experimental (symbols) and model predicted (lines) IDTs of the hexane isomers at $\varphi$ $=1, p=15$ bar and $X_{\mathrm{O} 2}=21 \%$, measured in an RCM (solid symbols) and in a HPST (open symbols),

The symbols in Figs. 2(a) and 2(b) present the IDTs of the hexane isomers (NHX, 2MP, 3MP, 22DMB and 23DMB) at $\varphi=1, p=15$ bar and $X_{\mathrm{O} 2}=21 \%$, measured in both the RCM and the HPST. On reviewing the raw data from the previous shock tube measurements of $n$-hexane [9], some unreported IDTs of $n$-hexane have been restored and are included in Fig. 2(a), using open symbols for convenience for comparison with the RCM values of IDT for the other hexane isomers. Overall, the agreement between the experimental results and the simulations shown in Fig. 2(a) is 
good, indicating that the different reactivities that result from the hexane molecular structures are generally well-predicted by the current model. Nevertheless, the model could be improved as suggested by certain deviations, especially those at the high temperature end in Fig. 2(a). However, it should also be noted that these deviations may be partly attributable to non-ideal effects in the experiments [36], and agreement between the IDTs at the lowest temperature end of the shock tube section is excellent.

All five hexane isomers show pronounced negative temperature coefficient (NTC) behavior at low temperatures, below 950K. The largest differences in reactivities between the hexane isomers are observed in the temperature interval between 700 and $900 \mathrm{~K}$ ), while these differences virtually disappear at the highest temperatures ( 1000 K) in Fig. 2(a). In general, $n$-hexane is the most reactive isomer over the entire low and intermediate temperature range (i.e. below $950 \mathrm{~K}$ ). The IDTs for 2MP and 3MP are very similar and both are longer than for $n$-hexane, the IDTs of 22DMB are longer than for 2MP and 3MP by a factor of three in the NTC region, and the IDTs of 23DMB are a further factor of three longer again compared to 22DMB. These trends correlate with their Research Octane Numbers (RONs) and are consistent with the observations of Wang et al. [6], in which $\mathrm{NHX}<2 \mathrm{MP} \sim 3 \mathrm{MP}<22 \mathrm{DMB}<23 \mathrm{DMB}$ in the order of resistance to auto-ignition, as seen in the legend in Fig. 2 for the RON and MON numbers [37] of the hexane isomers. At around $880 \mathrm{~K}$, a crossover in the reactivities of 22DMB and 23DMB is observed, where the IDTs of 22DMB are almost equal to those of 23DMB and become longer than for 23DMB at higher temperatures. This crossover and high temperature similarity in IDT correlates with the Motored Octane Numbers (MON) of 22DMB and 23DMB, which are virtually identical (i.e., 93.4 and 94.2, 
respectively). MON is determined under higher engine speed (900 RPM) and higher intake temperatures $\left(149{ }^{\circ} \mathrm{C}\right.$ ) compared to that for RON tests (engine speed at 600 RPM and intake temperature at $52{ }^{\circ} \mathrm{C}$ ), so MON tests involve higher combustion temperatures than RON tests. Accordingly, the region in the RCM data that correlates with MON is expected to be at elevated temperatures. In contrast, RON tests reflect reactivity at temperatures somewhat lower than the MON tests, and the RON value of 104.3 for 23DMB is considerably larger than the RON value of 91.8 for 22DMB, which correlates with the wide differences between the IDTs for these hexane isomers for temperatures below about 850K in Fig.2(a). The similarity in MON for 22DMB and 23DMB, combined with the significant differences in their RON values, give 23DMB a relatively large Octane Sensitivity (OS) of 10, while the OS for 22DMB is very small ( $\sim 2)$. These correlations between octane numbers and kinetically computed ignition delay times provide an additional validation of the accuracy of the present merged mechanisms for the hexane isomers [38]. No pronounced crossovers are observed between the reactivities of 2MP and 3MP from the experimental data. Figure 2(a) shows that the reactivity of 2MP is only slightly higher than 3MP throughout the NTC region and into part of the low temperature region, which is well-reproduced by the model, and this is also consistent with the fact that values of RON and MON for 2MP and 3MP are all within the range of $73.3-74.5$.

At around $1000 \mathrm{~K}$, which is the high temperature end in Fig 2(a), the differences in RCM reactivities of all five hexane isomers are very small. This trend is consistent with the HPST results also performed at 15 bar as shown in Fig 2(b). The HPST results for $n$-hexane from [9] are also included in Fig. 2(b), and the very close similarity in ignition delay times persists to at least 1400K 
in Fig. 2(b). Similar observations of great similarity in high temperature shock tube ignition delays for stoichiometric fuel/air isomers of heptane $[12,13]$ and $n$-alkanes from $n$-heptane to $n$ hexadecane [39] in air have been predicted and observed experimentally [22], with the similarities for stoichiometric alkane/air mixtures extending to at least 1500K [13] for heptane isomers. Interestingly, these very close similarities in shock tube IDT for n-alkanes disappear when fuel/rich $n$-alkane/air mixtures are examined [21], and variabilities in shock tube IDT for families of alkane isomers for non-stoichiometric fuel/air mixtures have not been explored, so further experimental studies of ignition of non-stoichiometric hexane isomer/air mixtures are warranted.

The first-stage IDTs were measured in the RCM for the four branched hexane isomers at $\varphi=$ 1, $p=15$ bar and $X_{\mathrm{O} 2}=21 \%$, depicted as symbols in Fig. 3, combined with corresponding results for $n$-hexane [9] for comparison as in Fig. 2(a). The computed first stage IDTs follow very similar trends as indicated in Fig. 3, with the first stage IDTs of 2MP, 3MP and 22DMB all quite similar, while those of NHX and 23DMB are the shortest and longest, respectively. The model reproduces well the first stage IDTs and these trends, indicating that the current reaction rate rules describe adequately the low temperature chemical behavior of the hexane isomers. This validates a portion of the kinetic mechanisms for the hexane isomers that is distinct from that of the full ignition simulations, where the first stage is much more influenced by the low temperature initiation and pyrolysis classes of reactions than the oxidation and alkylperoxy radical isomerization reaction pathways that lead to eventual ignition. 


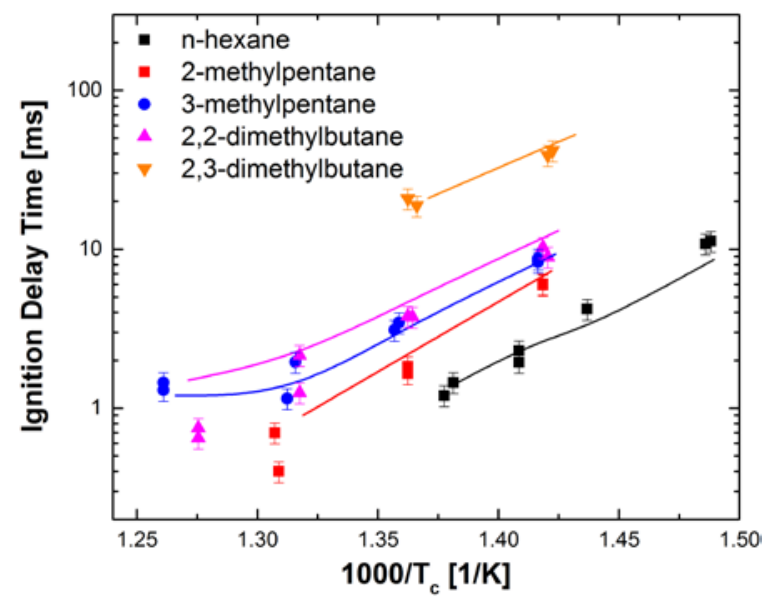

Fig. 3. Experimental (symbols) and model predicted (lines) first stage IDTs of hexane isomers measured in RCM at $\varphi=1, p=15$ bar and $X_{\mathrm{O} 2}=21 \%$.

Reaction pathway analysis diagrams of NHX, 2MP, 3MP, 22DMB and 23DMB are shown in Figs. 4(a)-(c) and Figs. 5(a), (b), respectively, based on rate of production (ROP) analyses (assuming constant volume conditions) for the ignition of the fuels at $800 \mathrm{~K}$ and $1100 \mathrm{~K}$, at 20\% fuel consumed. The percentage contributions for all of the reaction pathways are shown in red italic numbers $(T=800 \mathrm{~K})$ and black underlined numbers $(T=1100 \mathrm{~K})$ and are presented to highlight the major reaction pathways and illustrate the competition between chain branching and chain propagation processes.

It may help the reader if we provide an example of how to interpret these reaction pathways, using 2MP and Fig. 4(b) as an example. At 800K, 21.8\% (i.e., 21.8) of the fuel reacts to produce the IC6-4 alkyl radical. This is the pathway shown as the fourth from the top of the five paths for the 2MP fuel in Fig. 4(b). While 14.9 (14.9\%) of these radicals decompose to produce propene and iso-propyl radical, $82.6(82.6 \%)$ add to $\mathrm{O}_{2}$ to produce the IC6-4OO radical, then $76.3(76.3 \%)$ of these radicals internally abstract an $\mathrm{H}$ atom from the tertiary site. Of these specific QOOH radicals, 40.3 (40.3\%) then produce a cyclic ether and 55.0 (55.0\%) produce the $\mathrm{O}_{2} \mathrm{QOOH}$ radical, and 98.0 
(98.0\%) of these lead to chain branching.

Besides the formation of carbonyl-hydroperoxides (chain branching) and the olefin $+\mathrm{HO}_{2}$ elimination (chain propagation), the alternative isomerization pathways $[16,33,34]$ have also been considered in the current model through which $\dot{\mathrm{O}}_{2} \mathrm{QOOH}$ radicals isomerize to di-hydroperoxyl alkyl radicals $\dot{\mathrm{P}}(\mathrm{OOH})_{2}$. The consumption of $\dot{\mathrm{P}}(\mathrm{OOH})_{2}$ radicals can be chain propagating or chain branching depending on the exact structure of the $\dot{\mathrm{P}}(\mathrm{OOH})_{2}$ decomposition products. As mentioned previously, $\dot{\mathrm{P}}(\mathrm{OOH})_{2}$ can form hydroperoxyl cyclic ethers which eventually lead to chain branching. For the di-hydroperoxyl alkyl radicals with hydroperoxyl groups on the beta sites of the radical, $\beta$-scission of the $\mathrm{C}-\mathrm{O}$ bond produces $\mathrm{HO}_{2}$ radicals and alkenyl hydroperoxides. Although the subsequent decomposition of alkenyl hydroperoxides produce $\dot{\mathrm{OH}}$ radicals, $\mathrm{HO}_{2}$ radicals are not as reactive in the low temperature region where the importance of alternative isomerization pathways is confined. Thus, the production of alkenyl hydroperoxides, from either $\dot{\mathrm{O}}_{2} \mathrm{QOOH}$ or $\dot{\mathrm{P}}(\mathrm{OOH})_{2}$ radicals, is chain propagating when $\mathrm{HO}_{2}$ radicals are produced. Most of the other decomposition pathways of $\dot{\mathrm{P}}(\mathrm{OOH})_{2}$ radicals eventually produce one $\dot{\mathrm{O}} \mathrm{H}$ radical from each hydroperoxyl group and contribute to chain branching. Therefore, whether the reaction contributes to chain propagation or branching depends on whether or not $\dot{\mathrm{HO}}_{2}$ or $\dot{\mathrm{O}} \mathrm{H}$ radicals are produced from the peroxyl or hydroperoxyl groups. For clarity, the consumption pathways of $\dot{\mathrm{O}}_{2} \mathrm{QOOH}$ have been simplified in Figs. 4 and 5, with the pathways producing $\mathrm{HO}_{2}+$ alkenyl hydroperoxides labelled “chain propagating” with other pathways labelled “chain branching”.

In the NTC region ( $T=700-900 \mathrm{~K}$ ), low-temperature chain branching processes are important for all hexane isomers. Fuel radicals are mainly consumed by addition to $\mathrm{O}_{2}$, and the flux going 
through the addition of $\dot{\mathrm{QOOH}}$ to $\mathrm{O}_{2}$ is considerable, although strong competition can be observed for $\mathrm{HO}_{2}$ elimination from $\mathrm{RO}_{2}$, cyclic ether formation and $\beta$-scission of $\dot{\mathrm{QOOH}}$ radicals. On the other hand, the magnitude of the competition from chain propagating pathways differs according to fuel structure, as indicated by the comparison between the isomers. For example, the addition of $\mathrm{QOOH}$ to $\mathrm{O}_{2}$ is a critical step for the chain branching process, and in Fig. 5 it is shown that addition of $\dot{\mathrm{Q} O O H}$ radicals from 22DMB and 23DMB to $\mathrm{O}_{2}$ receives more competition from cyclic ether formation, concerted $\mathrm{HO}_{2}$ elimination and $\beta$-scission than those from NHX, 2MP and 3MP. QOOH radicals from NHX show the highest flux through addition to $\mathrm{O}_{2}$. The production of some fuel radicals has pronounced contributions to chain branching via reaction sequences such as those that start from the secondary radicals in NHX, 2MP and 3MP and result in chain branching. Meanwhile, the secondary radical of $2 \mathrm{MP}$ with a tertiary carbon on the $\gamma$ site $(\mathrm{CC}(\mathrm{C}) \mathrm{CC} \cdot \mathrm{C})$ contributes much more to chain branching than the other secondary radical. Actually, this is a common trend indicated in Figs. 4 and 5, in that $\mathrm{RO}_{2}$ or $\dot{\mathrm{O}}_{2} \mathrm{QOOH}$ radicals with secondary or tertiary carbons on the $\gamma$ site of the peroxyl groups tend to have more flux leading through chain branching pathways. This is because the inner hydrogen transfer favors six-membered ring transition states and secondary/tertiary carbons. On the other hand, when such conditions are not possible, $\dot{\mathrm{O}}_{2}$ or $\dot{\mathrm{O}}_{2} \mathrm{QOOH}$ radicals are consumed more via chain propagation rather than via chain branching reactions. This is especially true when there are multiple $\beta$ carbons that bear hydrogen atoms, so concerted $\mathrm{HO}_{2}$ elimination from $\mathrm{RO}_{2}$ radicals is more competitive, such as the case of the tertiary radicals of 3MP and 23DMB. In some cases, the formation of cyclic ethers can also become highly competitive in the consumption of Q QOOH radicals. Yet it should be noted that, 
although concerted $\mathrm{HO}_{2}$ elimination from $\mathrm{RO}_{2}$ radicals and the formation of cyclic ethers from Q̇OOH radicals are both chain propagation steps and inhibit chain branching, the former often has a larger effect in reducing fuel reactivity, as $\mathrm{HO}_{2}$ radicals are less reactive than the $\dot{\mathrm{OH}}$ radicals produced by cyclization. Thus, the contribution of each fuel radical to the low temperature reactivity not only depends on the type of the radical site, but also on the local structure, as the latter factor affects the competition between chain propagation and chain branching processes. These trends in the reaction flux of the hexane isomers are related to their different reactivities in the NTC regime, as observed in the RCM experiments. All of the above distinctions in reaction pathways in the low temperature regime produce the observed different overall reactivities of the hexane isomers and ultimately are responsible for their wide range in octane numbers, which range from 24 to 104. 
(a)

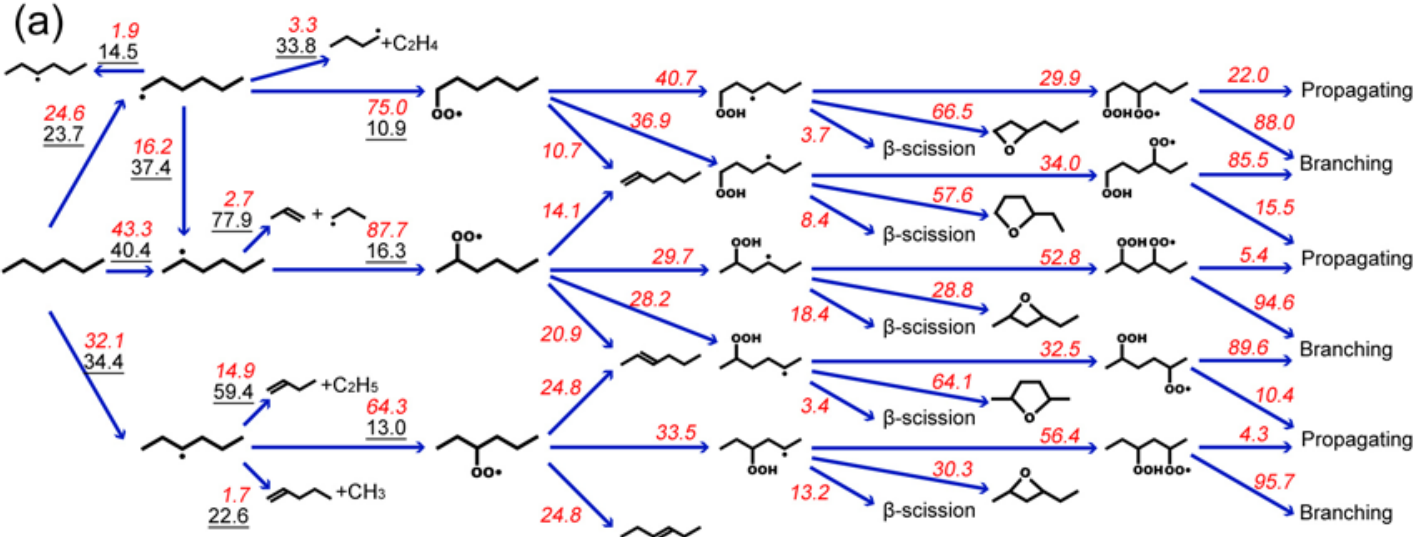

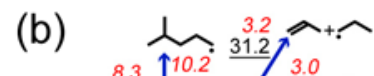

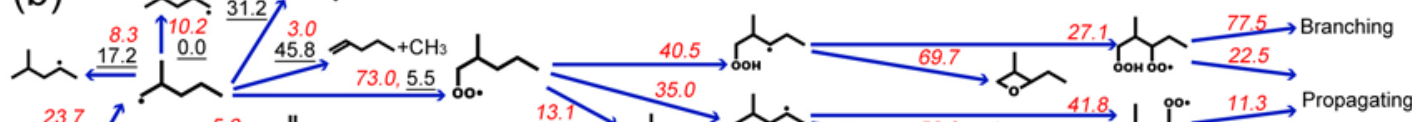

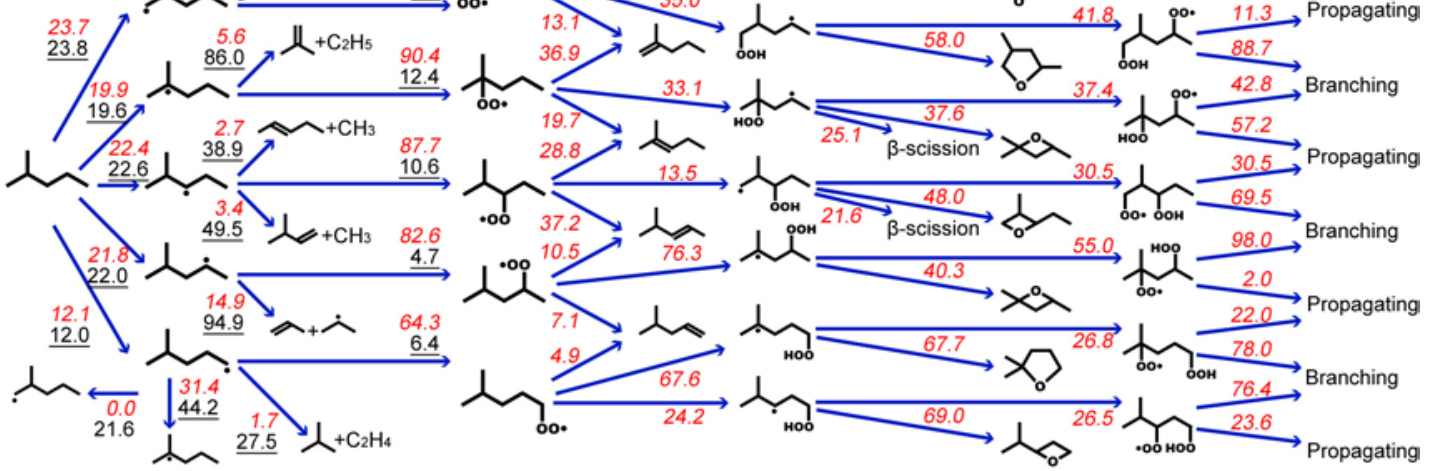

(c) $\quad{ }_{95.9}^{18.1} \dot{\sim}^{+{ }^{+C H}+4}$

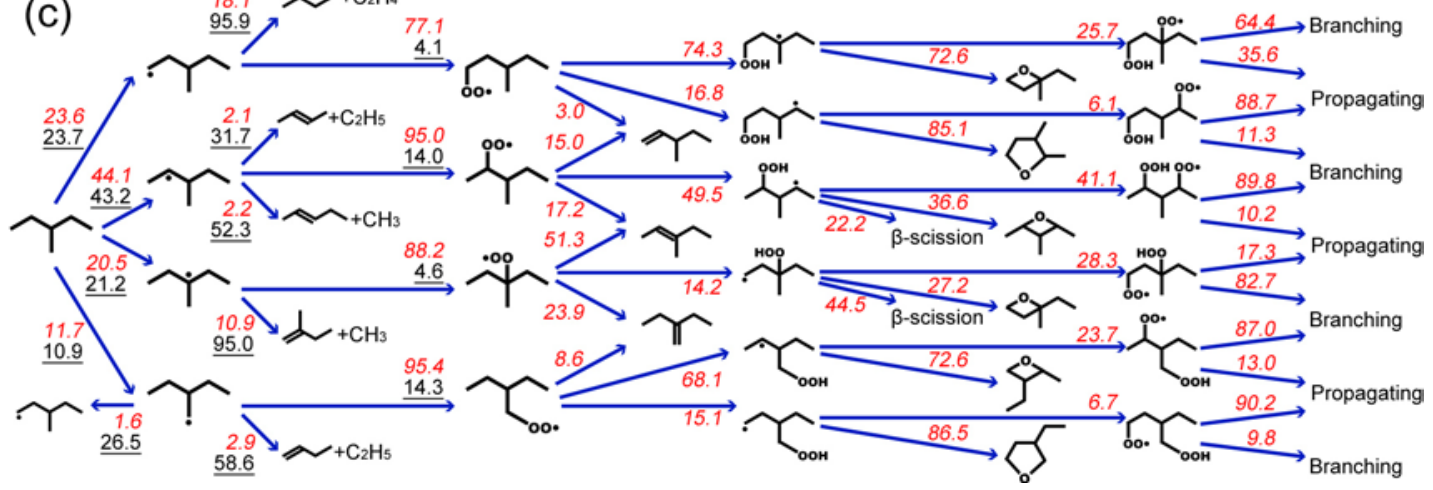

Fig. 4. Reaction pathway diagrams of (a) n-hexane, (b) 2-methylpentane, (c) 3-

methylpentane based on the rate of production analysis at stoichiometric condition, $p=15$ bar, $T$

$=800 \mathrm{~K}$ and $1100 \mathrm{~K}$, respectively. Percentages of contribution are marked in red italic (800 K)

and black underlined numbers (1100 K). 

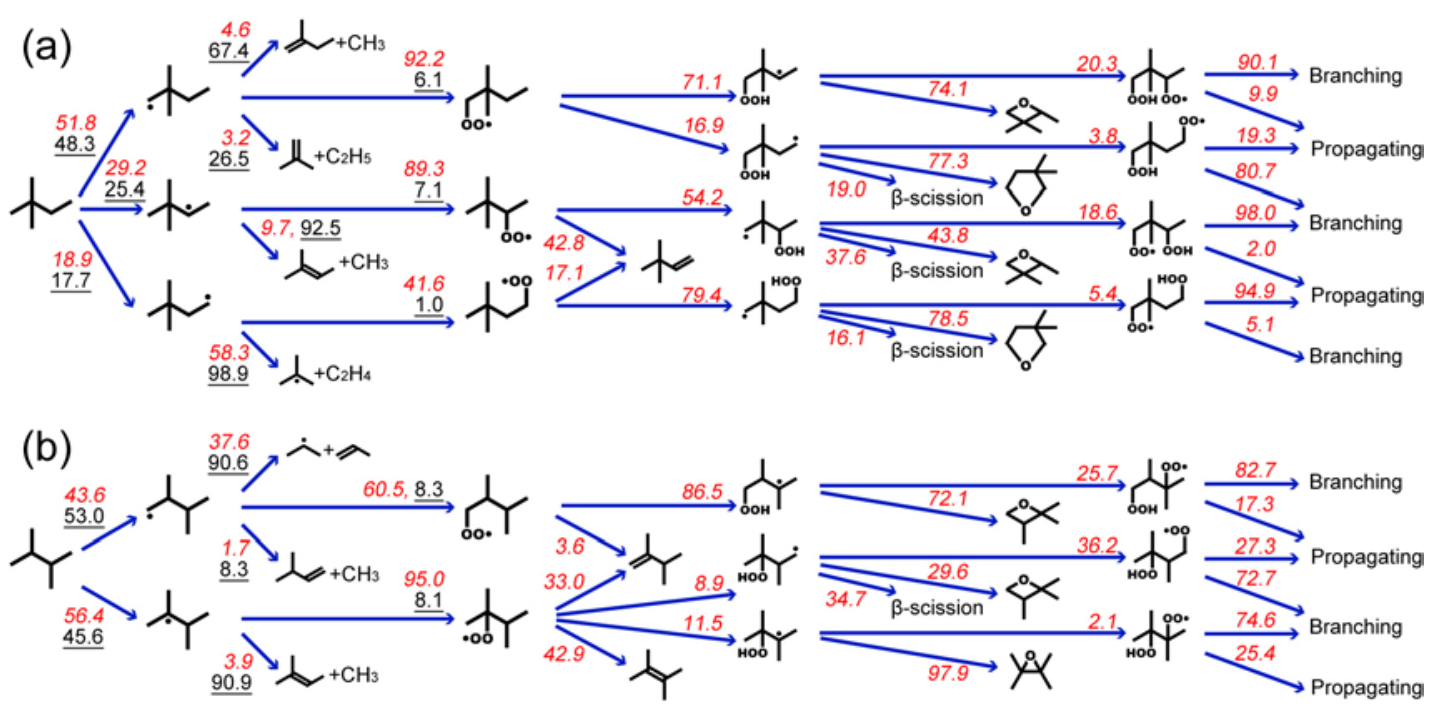

Fig. 5. Reaction pathways of (a) 2,2-dimethlybutane and (b) 2,3-dimethylbutane based on rate of production analysis at $\varphi=1, p=15 \mathrm{bar}, T=800 \mathrm{~K}$ and $1100 \mathrm{~K}$, respectively. Percentages of contribution are marked in red italic $(800 \mathrm{~K})$ and black underlined numbers $(1100 \mathrm{~K})$.

Comparison of the reaction pathways of the fuel computed from the model can reveal the specific structures that promote or inhibit reactivity. The overall flux of each fuel radical leading to chain branching can be estimated by the product of multiplying all contribution percentages along the relevant pathways starting from the addition of fuel radical to $\mathrm{O}_{2}$, as shown in Table 2 . For example, the chain branching estimate for the IC6-4 radical is $(0.826 * 0.763 * 0.550 * 0.980$ $=0.34$ ), equal to the Flux term in Table 2 for the iC6-4fuel radical. The corresponding calculation for the IC6-5 radical gives $(0.643 * 0.676 * 0.268 * 0.78=0.09)$, lower than the 0.12 value in Table 2. However, closer examination of Fig. 4(b) shows a second path initiated by the IC6-5 radical from a second isomerization reaction of the $\mathrm{QOOH}$ radical to abstract an $\mathrm{H}$ atom from the '3' site (the above calculation used QOOH abstracting an $\mathrm{H}$ atom from the tertiary, '2' site), giving $(0.643 * 0.242 * 0.265 * 0.76 .4=0.03)$. When added to the other pathway for the IC6-5 radical, the resulting total of 0.12 agrees with the total Flux value in Table 2. This means the branching 
ratios in the production of different fuel radicals largely affect the reactivity of the current model in the NTC region, because only some of them contribute efficiently to chain branching. Using 2MP for example, production of iC6-4 radicals leads most efficiently to chain branching, followed by production of iC6-5 radicals while iC6-2 and iC6-3 radicals contribute less to chain branching, or may even inhibit chain branching since they compete with the production of iC6-4 radicals. To compare between different fuel radicals, the flux that contributes to chain branching has been calculated and shown as column "Flux" in Table 2. It can be seen in Table 2 that NHX has the highest total flux that contributes to chain branching, followed by 2MP and 3MP which are very similar, while that of 22DMB is higher than the most unreactive isomer 23DMB; this is consistent with model predictions and the experimental observations. This type of comparison can identify the sources of the different low temperature reactivities of the hexane isomers from the perspective of kinetic modeling.

At $1100 \mathrm{~K}$ (Figs. 4 and 5), the low-temperature chemistry is no longer dominant. At higher temperatures, fuel radicals readily decompose via $\beta$-scission, forming a pool of smaller species that are common to all of the hexane isomers. This common pool of smaller radical species increases the similarities between the combustion rates and reaction pathways of the different hexane isomers, and at higher temperatures, a different group of small molecule elementary reactions are responsible for chain branching and ignition, and this will be discussed below. 
Table 2. The overall flux of each fuel radical leading to chain branching process based on reaction flux analysis at $p=15 \mathrm{bar}, T=800 \mathrm{~K}$ and $20 \%$ fuel consumption.

\begin{tabular}{|c|c|c|c|c|}
\hline Fuel & Fuel radical & Name & Flux & Total \\
\hline \multirow{3}{*}{ NHX } & $\mathrm{C} \cdot \mathrm{CCCCC}$ & C6H13-1 & $15.7 \%$ & \multirow{3}{*}{$14.8 \%$} \\
\hline & $\mathrm{CC} \cdot \mathrm{CCCC}$ & C6H13-2 & $13.0 \%$ & \\
\hline & ССС $\bullet$ ССС & C6H13-3 & $16.4 \%$ & \\
\hline \multirow{5}{*}{$2 \mathrm{MP}$} & $\mathrm{C} \cdot \mathrm{C}(\mathrm{C}) \mathrm{CCC}$ & iC6-1 & $6.1 \%$ & \multirow{5}{*}{$13.1 \%$} \\
\hline & $\mathrm{CC} \cdot(\mathrm{C}) \mathrm{CCC}$ & iC6-2 & $5.4 \%$ & \\
\hline & $\mathrm{CC}(\mathrm{C}) \mathrm{C} \cdot \mathrm{CC}$ & iC6-3 & $4.5 \%$ & \\
\hline & $\mathrm{CC}(\mathrm{C}) \mathrm{CC} \cdot \mathrm{C}$ & iC6-4 & $34.2 \%$ & \\
\hline & $\mathrm{CC}(\mathrm{C}) \mathrm{CCC} \bullet$ & iC6-5 & $12.1 \%$ & \\
\hline \multirow{4}{*}{ 3MP } & $\mathrm{C} \cdot \mathrm{CC}(\mathrm{C}) \mathrm{CC}$ & i3C6-1 & $11.4 \%$ & \multirow{4}{*}{$13.2 \%$} \\
\hline & $\mathrm{CC} \cdot \mathrm{C}(\mathrm{C}) \mathrm{CC}$ & i3C6-2 & $19.5 \%$ & \\
\hline & $\mathrm{CCC} \cdot(\mathrm{C}) \mathrm{CC}$ & i3C6-3 & $2.9 \%$ & \\
\hline & $\mathrm{CCC}(\mathrm{C} \cdot) \mathrm{CC}$ & i3C6-4 & $11.6 \%$ & \\
\hline \multirow{3}{*}{ 22DMB } & $\mathrm{C} \cdot \mathrm{C}(\mathrm{C})(\mathrm{C}) \mathrm{CC}$ & NEC6-1 & $12.8 \%$ & \multirow{3}{*}{$9.5 \%$} \\
\hline & $\mathrm{CC}(\mathrm{C})(\mathrm{C}) \mathrm{C} \cdot \mathrm{C}$ & NEC6-3 & $8.8 \%$ & \\
\hline & $\mathrm{CC}(\mathrm{C})(\mathrm{C}) \mathrm{CC} \bullet$ & NEC6-4 & $1.7 \%$ & \\
\hline \multirow{2}{*}{ 23DMB } & $\mathrm{C} \cdot \mathrm{C}(\mathrm{C}) \mathrm{C}(\mathrm{C}) \mathrm{C}$ & XC6-1 & $11.0 \%$ & \multirow{2}{*}{$6.0 \%$} \\
\hline & $\mathrm{CC} \cdot(\mathrm{C}) \mathrm{C}(\mathrm{C}) \mathrm{C}$ & XC6-2 & $2.2 \%$ & \\
\hline
\end{tabular}

A brute-force sensitivity analysis of predicted IDTs was performed at $T=704 \mathrm{~K}, 800 \mathrm{~K}$ and $1100 \mathrm{~K}, p=15$ bar, at $\varphi=1.0$, assuming constant volume conditions. Figures 6(a)-(e) present the ten most sensitive reactions for the ignition of NHX, 2MP, 3MP, 22DMB and 23DMB at each temperature. Reactions with positive sensitivity coefficients inhibit reactivity because increasing its rate produces a longer ignition delay time, while those with negative coefficients promote reactivity. In general, the most sensitive reactions at all three temperatures are the reactions of fuel molecules with OH radicals that produce alkyl radicals. Table 2 shows that the selectivity of this specific fuel radical production path, $\mathrm{H}$ atom abstraction from the fuel, can greatly affect the flux that leads to chain branching and low temperature reactivity, especially for the branched isomers. 
This trend is also reflected by the sensitivity analysis at low and intermediate temperatures. Depending on the contribution to chain branching, the production of fuel alkyl radicals can be quite sensitive in promoting or inhibiting reactivity for the branched isomers, while this trend is less pronounced for NHX since the three fuel radicals have comparable contributions to chain branching, as shown in Table 2. Other important reactivity-promoting reactions are the key steps in chain branching, such as the addition of $\dot{\mathrm{QOOH}}$ to molecular oxygen, as well as the formation and decomposition of carbonyl-hydroperoxides. As shown in Figs. 6(a) and (b), the decompositions of hydroperoxyl cyclic ethers are also sensitive reactions that promote reactivity, indicating that it is reasonable to lump this reaction class as being "chain branching" in the reaction flux diagram. The most reactivity-inhibiting reactions include the reactions that contribute to chain propagation such as concerted $\mathrm{HO}_{2}$ elimination reactions and the formation of cyclic ethers. At $T$ $=800 \mathrm{~K}, \mathrm{HO}_{2}$ radical chemistry becomes more important as its production from concerted $\mathrm{HO}_{2}$ elimination increases. The hydrogen abstraction of fuel by $\mathrm{HO}_{2}$ radical leads to the formation of a $\mathrm{H}_{2} \mathrm{O}_{2}$ molecule which decomposes into two $\dot{\mathrm{OH}}$ radicals and promotes reactivity. 
(a)

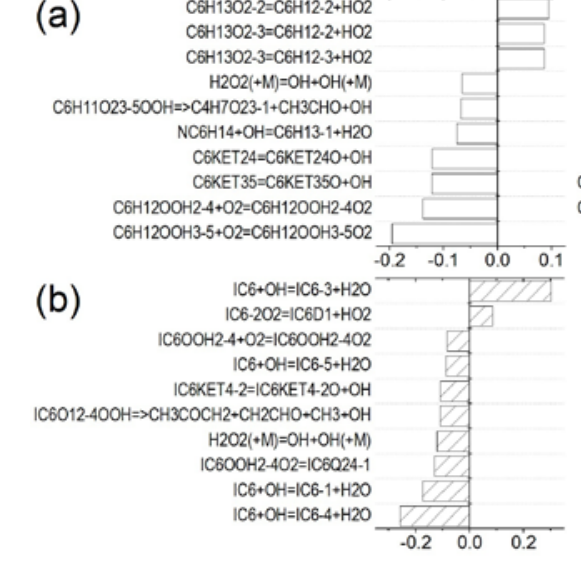

(c)

(d)

(e)
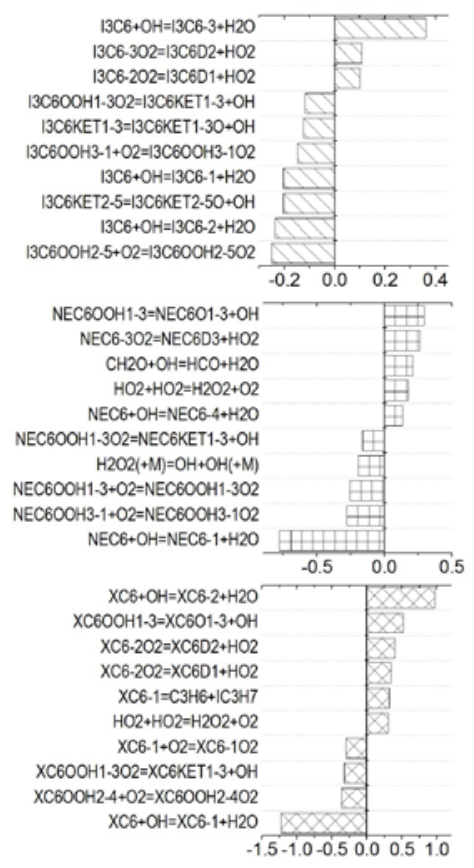

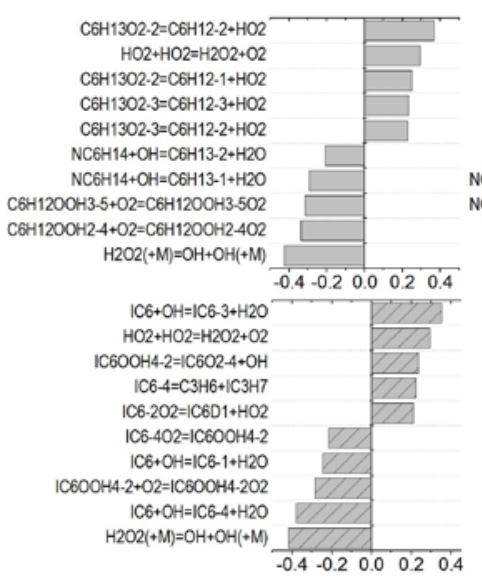

$13 \mathrm{C} 6+\mathrm{OH}=13 \mathrm{C} 6-3+\mathrm{H} 2 \mathrm{O}$

$13 \mathrm{C} 6-2 \mathrm{O} 2=13 \mathrm{C} 6 \mathrm{D} 1+\mathrm{HO} 2$

13 $6-2 \mathrm{O} 2=13 \mathrm{C} 6 \mathrm{D} 2+\mathrm{HO} 2$

$\mathrm{HO} 2+\mathrm{HO}_{2}=\mathrm{H}_{2} \mathrm{O} 2+\mathrm{O} 2$

$13 \mathrm{C} 600 \mathrm{H} 1-3=13 \mathrm{C} 601-3+\mathrm{OH}$

13C6-302=13C6D2+HO2

$13 \mathrm{C} 6+\mathrm{OH}=13 \mathrm{C} 6-1+\mathrm{H} 2 \mathrm{O}$

$\mathrm{H} 2 \mathrm{O} 2(+\mathrm{M})=\mathrm{OH}+\mathrm{OH}(+\mathrm{M})$

$13 \mathrm{C} 60 \mathrm{OH} 2-5+02=13 \mathrm{C} 60 \mathrm{OH} 2.5 \mathrm{O} 2$

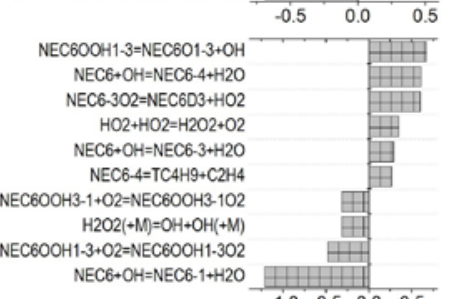

$\mathrm{NEC} 6 * \mathrm{OH}=\mathrm{NEC6}-1+\mathrm{H} 2 \mathrm{O}$

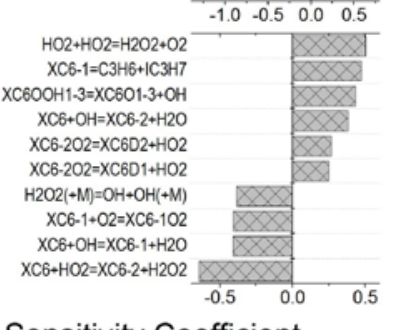

$13 \mathrm{C} 6+\mathrm{HO} 2=13 \mathrm{C} 6-2+\mathrm{H} 2 \mathrm{O} 2$

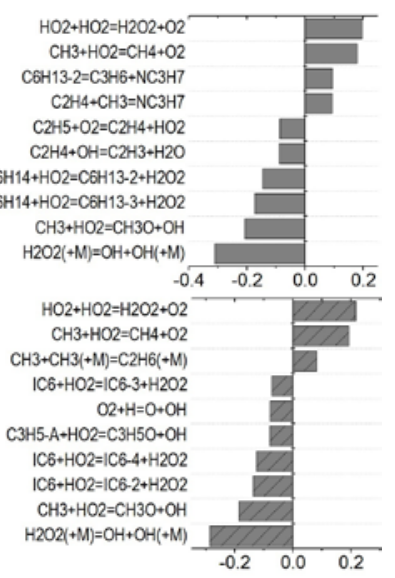

$\mathrm{CH} 3+\mathrm{HO}_{2}=\mathrm{CH} 4+\mathrm{O} 2$

$\mathrm{CH} 3+\mathrm{CH} 3(+\mathrm{M})=\mathrm{C} 2 \mathrm{H} 6(+\mathrm{M})$

$\mathrm{HO} 2+\mathrm{HO}_{2}=\mathrm{H}_{2} \mathrm{O} 2+\mathrm{O}_{2}$

I3C6-2 $=\mathrm{C} 5 \mathrm{H}$ 10-2 $2+\mathrm{CH} 3$

$\mathrm{SC} 4 \mathrm{H} 9=\mathrm{C} 3 \mathrm{H} 6+\mathrm{CH} 3$

$13 \mathrm{C} 6+\mathrm{HO} 2=13 \mathrm{C} 6-3+\mathrm{H} 2 \mathrm{O} 2$

$\mathrm{CH} 3 \mathrm{O} 2+\mathrm{CH} 3=\mathrm{CH} 3 \mathrm{O}+\mathrm{CH} 3 \mathrm{O}$

13C6+HO2 $=13 \mathrm{C} 6-2+\mathrm{H} 2 \mathrm{O} 2$

$\mathrm{CH} 3+\mathrm{HO} 2=\mathrm{CH} 3 \mathrm{O}+\mathrm{OH}$

$\mathrm{H} 2 \mathrm{O} 2(+\mathrm{M})=\mathrm{OH}+\mathrm{OH}(+\mathrm{M})$

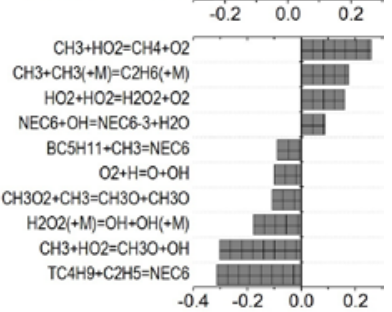

$\mathrm{CH} 3+\mathrm{HO}_{2}=\mathrm{CH} 4+\mathrm{O} 2$

$\mathrm{HO} 2+\mathrm{HO}_{2}=\mathrm{H} 2 \mathrm{O} 2+\mathrm{O} 2$

$\mathrm{XC} 6+\mathrm{OH}=\mathrm{XC6}-2+\mathrm{H} 2 \mathrm{O}$

$\mathrm{XC6}+\mathrm{HO} 2=\mathrm{XC6}-1+\mathrm{H} 2 \mathrm{O} 2$

$\mathrm{C} 3 \mathrm{H} 5-\mathrm{A}+\mathrm{HO} 2=\mathrm{C} 3 \mathrm{H} 5 \mathrm{O}+\mathrm{OH}$

IC $3 \mathrm{H} 7+1 \mathrm{C} 3 \mathrm{H} 7=\mathrm{XC6}$

$\mathrm{XC} 6+\mathrm{OH}=\mathrm{XC} 6-1+\mathrm{H} 2 \mathrm{O}$

$\mathrm{XC6}+\mathrm{HO} 2=\mathrm{XC} 6-2+\mathrm{H} 2 \mathrm{O} 2$

$\mathrm{H} 2 \mathrm{O} 2(+\mathrm{M})=\mathrm{OH}+\mathrm{OH}(+\mathrm{M})$

$\mathrm{CH} 3+\mathrm{HO}_{2}=\mathrm{CH} 3 \mathrm{O}+\mathrm{OH}$

Sensitivity Coefficient
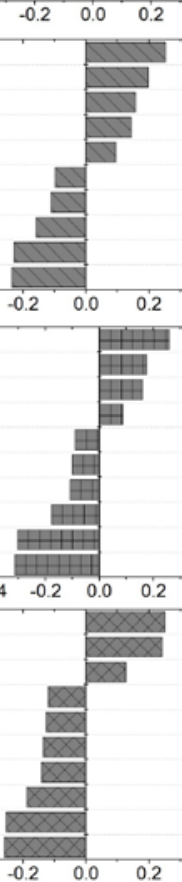

Fig. 6. Sensitivity analysis of the ignition of (a) NHX, (b) 2MP, (c) 3MP, (d) 22DMB and (e) 23DMB at $P=15$ bar, stoichiometric fuel/air mixtures, left column: $T=704 \mathrm{~K}$, middle column $T$ $=800 \mathrm{~K}$, right column: $T=1100 \mathrm{~K}$.

At $1100 \mathrm{~K}$, the sensitive reactions stem mostly from the chemistry of smaller species in the $\mathrm{C}_{0}-\mathrm{C}_{2}$ system, which emphasizes the significance of the base chemistry in predicting the reactivity of fuels at higher temperatures, particularly the reactions that involve the small radicals $\mathrm{OH}, \mathrm{H}, \mathrm{O}$, and $\mathrm{HO}_{2}$. Based on the information in Fig. 6, considerable intermediate temperature chain branching is provided by the sequence of reactions, important for each hexane isomer: 


$$
\begin{aligned}
& \mathrm{C}_{6} \mathrm{H}_{14}+\mathrm{HO}_{2}=\mathrm{H}_{2} \mathrm{O}_{2}+\mathrm{C}_{6} \mathrm{H}_{13} \\
& \mathrm{H}_{2} \mathrm{O}_{2}(+\mathrm{M})=\mathrm{OH}+\mathrm{OH}(+\mathrm{M})
\end{aligned}
$$

In addition, the reaction sequence

$$
\begin{aligned}
& \mathrm{CH}_{3}+\mathrm{HO}_{2}=\mathrm{CH}_{3} \mathrm{O}+\mathrm{OH} \\
& \mathrm{CH}_{3} \mathrm{O}=\mathrm{CH}_{2} \mathrm{O}+\mathrm{H}
\end{aligned}
$$

also provides significant chain branching by converting the weakly reactive radicals $\mathrm{CH}_{3}$ and $\mathrm{HO}_{2}$ into highly reactive radicals $\mathrm{H}$ and $\mathrm{OH}$. This computation at $1100 \mathrm{~K}$ is an illustration of the central role of the $\mathrm{H}_{2} \mathrm{O}_{2}$ species in delivering chain branching in this intermediate temperature regime [40] and the minimal role played by any species that is part of the alklyperoxy radical isomerization system that is dominant at lower temperatures.

In most hydrocarbon oxidation/ignition systems, the most important high temperature elementary reaction is the reaction of $\mathrm{H}$ atoms with $\mathrm{O}_{2}$ to produce $\mathrm{O}$ and $\mathrm{OH}$, a reaction that not only provides immediate chain branching, but also effectively mixes the radical pool in a way that is independent of the initial fuel species. This agrees with the experimental observations that the high temperature IDTs are similar for all five hexane isomers. The high temperature regime above $1100 \mathrm{~K}$ is dominated by the production of certain radicals, (e.g. ethyl and H), that promote reactivity at high temperatures via the $\mathrm{H}+\mathrm{O}_{2}=\mathrm{O}+\mathrm{OH}$ reaction, and others such as $\mathrm{CH}_{3}$, which effectively inhibits high temperature reactivity via the chain termination reaction $\mathrm{CH}_{3}+\mathrm{CH}_{3}=\mathrm{C}_{2} \mathrm{H}_{6}$.

Jet Stirred Reactor (JSR)

Wang et al. [6] investigated the oxidation of all five hexane isomers in a jet-stirred reactor at 
1.06 bar, stoichiometric condition, inlet fuel mole fraction of $2 \%$ and $4 \%$, and for a residence time of $2 \mathrm{~s}$. That elegant study measured essential species-specific mole fractions of many fuel, product, and intermediate species that provide valuable tests for kinetic modeling. Figures 7-9 show a considerable number of comparisons between many of those experimentally measured mole fractions and those calculated using the current hexane isomer kinetic models.

The reactivities of the hexane isomers at low temperatures follow trends that are consistent with those indicated by their ignition delay times. NHX shows the largest consumption of fuel at temperatures below $750 \mathrm{~K}$, followed by 2MP and 3MP with similar amounts of fuel consumed. In the same temperature region, very little consumption of the doubly-branched 22DMB or 23DMB is observed. The differences in reactivity between these isomers result from their distinct molecular structures, and their structures affect reaction pathways beginning with the very first elementary reaction. The most easily abstracted $\mathrm{H}$ atom in 23DMB is located at the tertiary site, and the most easily abstracted $\mathrm{H}$ atom in 22DMB is located at the only secondary site. Both heptyl radicals decompose preferentially via $\beta$-scission to produce the relatively stable olefin species $\mathrm{BC}_{5} \mathrm{H}_{10}$ (2methyl 2-butene) and a methyl radical, both of which slow subsequent reactivity and lead to long ignition delay times. In contrast, NHX and both singly-branched hexane isomers have multiple easily abstracted $\mathrm{H}$ atoms located at secondary and tertiary sites, which produce hexyl radicals that decompose rapidly and provide ignition delay times much shorter than those from 22DMB or 23DMB. In particular, 2MP, 3MP and NHX alkyl decomposition reactions produce a much higher fraction of ethyl radicals and $\mathrm{H}$ atoms than the doubly-branched isomers. The ethyl radicals and $\mathrm{H}$ 
atoms strongly support chain branching overall, while the methyl radicals and larger olefins produced by the 22DMB and 23DMB fuels retard subsequent reaction.
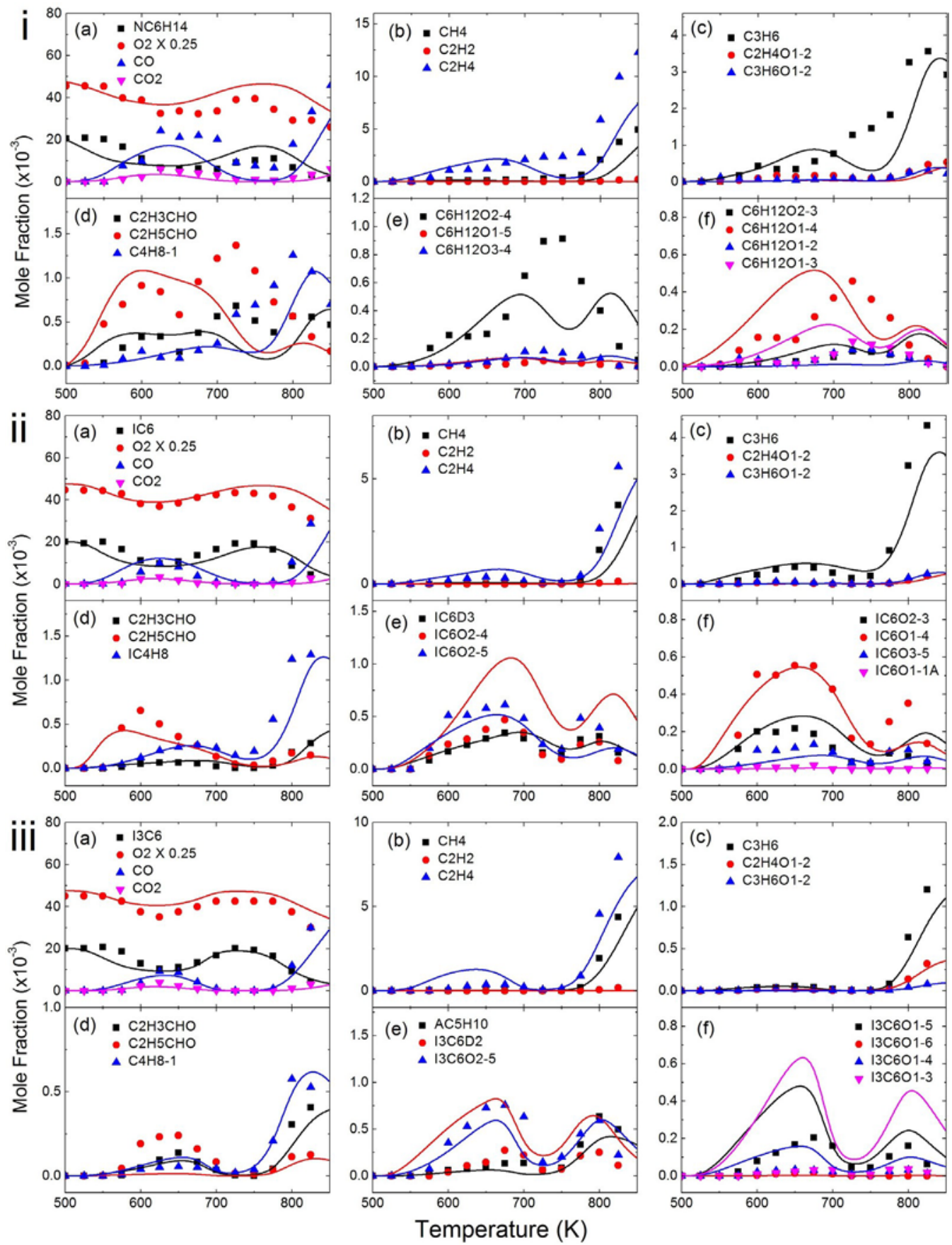

Fig. 7. Experimentally measured mole fraction profiles [6] and model predictions of species identified in the oxidation of (i) n-hexane, (ii) 2-methyl pentane, (iii) 3-methyl pentane in jet- 
stirred reactor, with an inlet fuel concentration of $2 \%$.

Differences in structure of the hexane isomers lead to differences in both their low temperature reactivities and their production of smaller, more reactive radical species at higher temperatures. A good example is that methane is formed as an intermediate when methyl radicals abstract $\mathrm{H}$ atoms from the fuel. Decomposition of alkyl radicals from fuels with numerous methyl side branches produce large numbers of methyl radicals, so production of methane is highest for the most highly-branched hexane isomers. Similarly, larger amounts of iso-butene are produced by the 22DMB and 23DMB than in the other isomers, and in general, the specific composition of the $\mathrm{C}_{2}-$ $\mathrm{C}_{5}$ species is closely related to the fuel structure that can produce these species. These trends
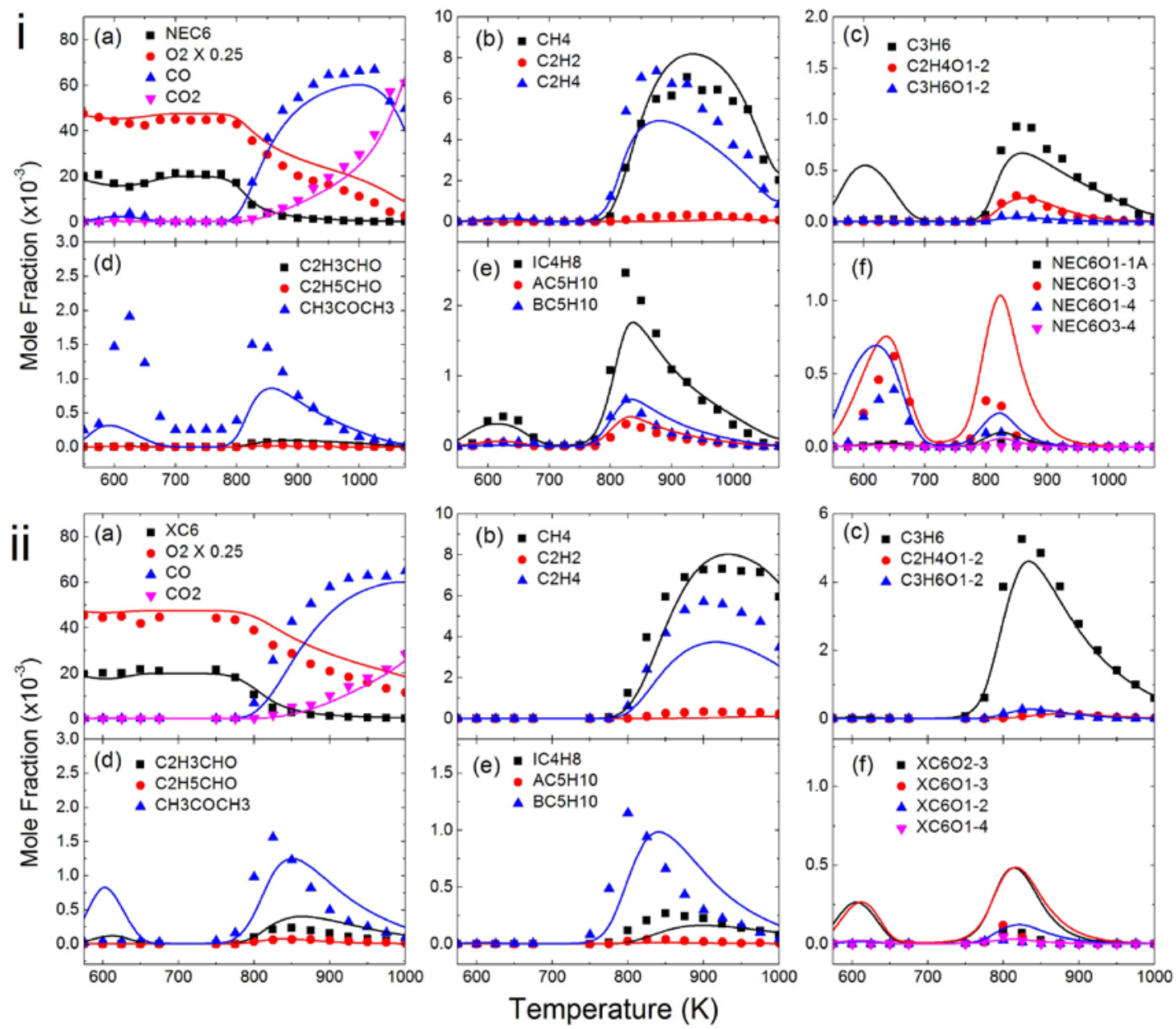
Fig. 8. Experimentally measured mole fraction profiles [6] and model predictions of species identified in the oxidation of (i) 2,2-dimethyl butane, (ii) 2,3-dimethyl butane in jet-stirred reactor, with an inlet fuel concentration of $2 \%$.

can be seen in the concentrations of methane, ethylene, propene and butene shown in Figs. 7 and 8, which are well captured by the current model.

It is also instructive to note that the species measurements for the more reactive isomers in Fig. 7 cover a lower range of temperatures than the corresponding range for 22DMB and 23DMB in Fig. 8, and the extents of reaction in the cool flame region of 500-800K are very much greater for the fuels in Fig. 7. The 22DMB and 23DMB measurements show extremely low levels of aldehyde intermediates while much higher aldehyde levels are produced, especially at temperatures around $600 \mathrm{~K}$, by the more reactive isomers. Overall, these species measurements illustrate how the more highly branched chain structures of 22DMB and 23DMB suppress low temperature, cool flame kinetics relative to the other hexane isomers, resulting in the higher octane numbers and octane sensitivities of the more branched isomers.

However, some deviations can be seen between experimental data and the model predictions of the JSR experiments. The most evident difference shows that the model predicts levels of propene $\left(\mathrm{C}_{3} \mathrm{H}_{6}\right)$ for all five hexane isomers and for both fuel inlet mole fractions of $2 \%$ and $4 \%$, that agree well with the experiments at all temperatures, except for the lowest temperatures around $600 \mathrm{~K}$ for the 22DMB system, where the experiments report zero mole fractions at both inlet fuel mole fraction levels. As the current model have not been optimized using these results, this may indicate that the current model can still be improved especially in the consumption of low 
temperature intermediates such as cyclic ethers. Detailed chemical kinetic models of these species are rarely reported. Meanwhile, further experimental works are needed as Wang et al. [6] noted the difficulties associated with quantified detection of propene mole fractions in their facilities by Time-Of-Flight Mass Spectrometry (TOF MS) or by gas chromatography (GC), largely due to the nearly equal molecular weights of propene and ketene.

A second example, Fig. 8 ii(f) shows the concentrations of the cyclic ethers identified in the oxidation of 23DMB are over-predicted at $2 \%$ inlet fuel concentration, in which the measurements show detectable levels for all of the 23DMB cyclic ethers for only two or three temperature values, while the kinetic model shows small but non-zero measurable mole fractions for two of the four C6 cyclic ethers. Yet when the inlet fuel concentration is $4 \%$, the agreement between experimentally measured and model-predicted concentrations of cyclic ethers in the 23DMB results becomes much better, as shown in Fig. 9(c) and Fig. 9(f). The higher fuel concentrations (4\%) in the Fig. 9 experiments, with an accordingly higher level of intermediate species levels, may also improve the precision available in these experiments at the lower levels of concentration, so these disagreements between model and experiment may not be serious. These observations suggest that the current model and reaction rate rules can still be improved, especially in the submodels of cyclic ethers. Due to the lack of comprehensive knowledge about the oxidation of cyclic ethers [41,42], this part of the chemistry is represented in the current model by lumped reactions with estimated reaction rates [14,17]. Therefore, experimental and theoretical studies of cyclic ether oxidation over a wider range of conditions, particularly at higher fuel levels, are needed to 
provide further insights into this process and optimize relevant kinetic models.
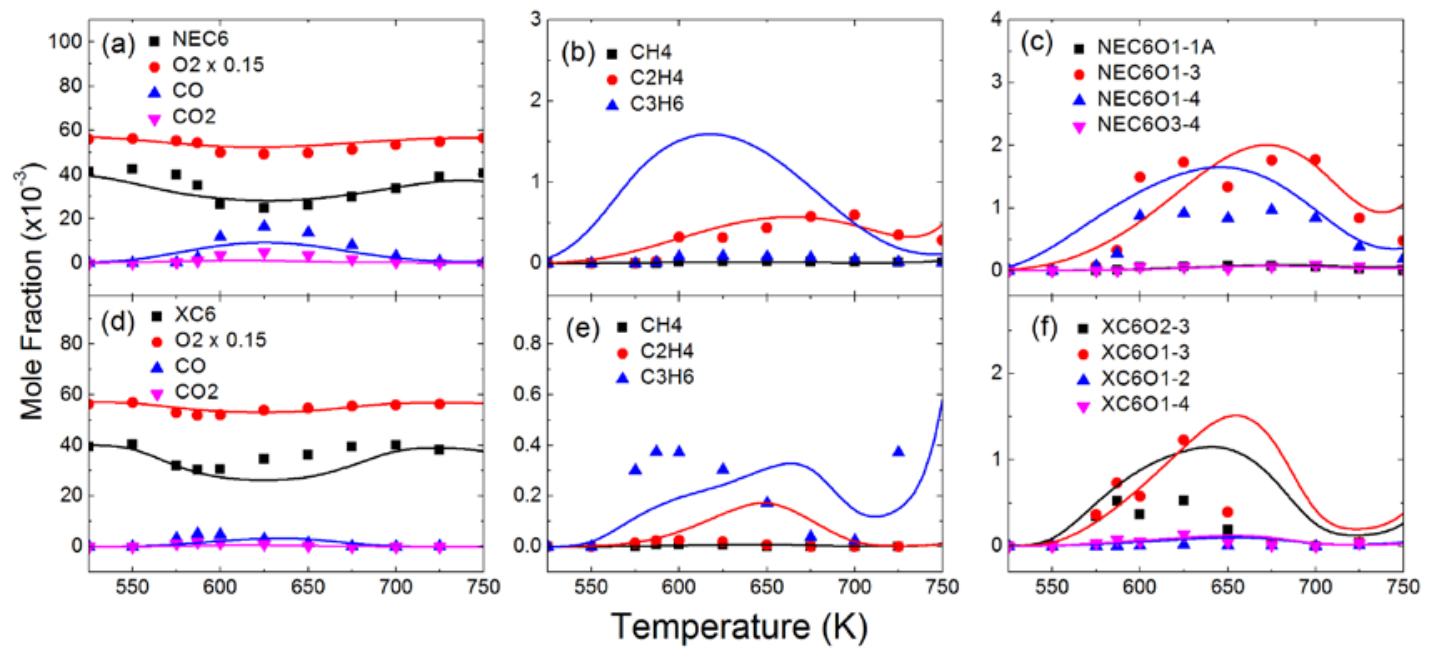

Fig. 9. Experimentally measured mole fraction profiles [6] and model predictions of species identified in the oxidation of (a-c) 2,2-dimethyl butane, (d-f) 2,3-dimethyl butane in jetstirred reactor, inlet fuel concentration at $4 \%$.

\section{Future Model Development}

In addition to a better understanding of and ability to model the kinetics of ignition and combustion of the isomers of hexane, a goal of the present work is to make progress towards a generalized set of reaction classes and rates that can be used simultaneously to simulate the combustion of isomers of other alkane fuels. In fact, as noted above, the present reaction rate rules have been developed and tested previously through their application to the mechanisms of many larger alkanes as large as $\mathrm{C}_{12} \mathrm{H}_{26}, \mathrm{C}_{15} \mathrm{H}_{32}, \mathrm{C}_{16} \mathrm{H}_{34}$ and $\mathrm{C}_{20} \mathrm{H}_{42}$. The current reaction rate rules are consistent but not identical with those used in a previously published $n$-heptane model [9], so that n-heptane model has been updated using the current reaction rate rules. Figure 10(a) shows the 
experimental [43] and simulated ignition delay times of $n$-heptane in air under a range of conditions, indicating that the updated model can well reproduce the ignition delay times measured in the experiments over a wide range of conditions. However, the $n$-heptane molecule does not contain any tertiary C-H bonds, so further tests were carried out with a branched alkane, iso-octane. The previously published LLNL iso-octane model [44] was updated using the present reaction rate rules and tested using experimental data of iso-octane ignition delay times reported by Atef et al. [16], which were measured at three different facilities. As indicated in Fig. 10(b), the experimental data sets are very consistent at the three test facilities and are well reproduced by the updated model. These validations support the possibility that the reaction rate rules proposed in this work can be applied to kinetic model development of larger alkanes. Yet more validations are needed for improve the reaction rate rules towards correctly reflecting the correlation between fuel structure and experimental fuel properties.

The primary purpose of the comparisons in Fig. 10 is simply to show that the unified kinetic mechanisms for $n$-hexane and branched alkane hexane fuels, using a single set of reaction pathway rules and rate expressions, appear to provide very good agreement between computed and experimental ignition delay time values not only for the present hexane isomers but also for other two widely studied large $n$-alkane and branched-chain alkane fuels without further modifications. This paper is not intended to be a kinetic study of any fuels except the hexane isomers. The specific example of $n$-heptane was selected for illustration because that particular paper by Ciezki and Adomeit [43] was the earliest systematic experimental presentation of the details of NTC behavior 
in ignition of alkane fuels and those data have been the subject of a very large number of lowtemperature kinetic modeling analyses since that 1993 paper; the reader looking for current research into n-heptane shock tube kinetics might consult excellent, very recent studies $[45,46]$ Similarly, the results in Fig. 10(b) are not intended as part of a comprehensive discussion of isooctane ignition, but rather as an illustration that the approach to reaction classes and rates taken from the present study of hexane isomers provides an acceptable description of iso-octane ignition in a single set of experimental conditions. In this case, the reader interested in current research in kinetics of iso-octane could begin productively with the paper of Atef et al. [16]. Both examples in Fig. 10 support the concept that the present approach may prove more general in its applicability to alkane fuels in addition to the isomers of hexane.
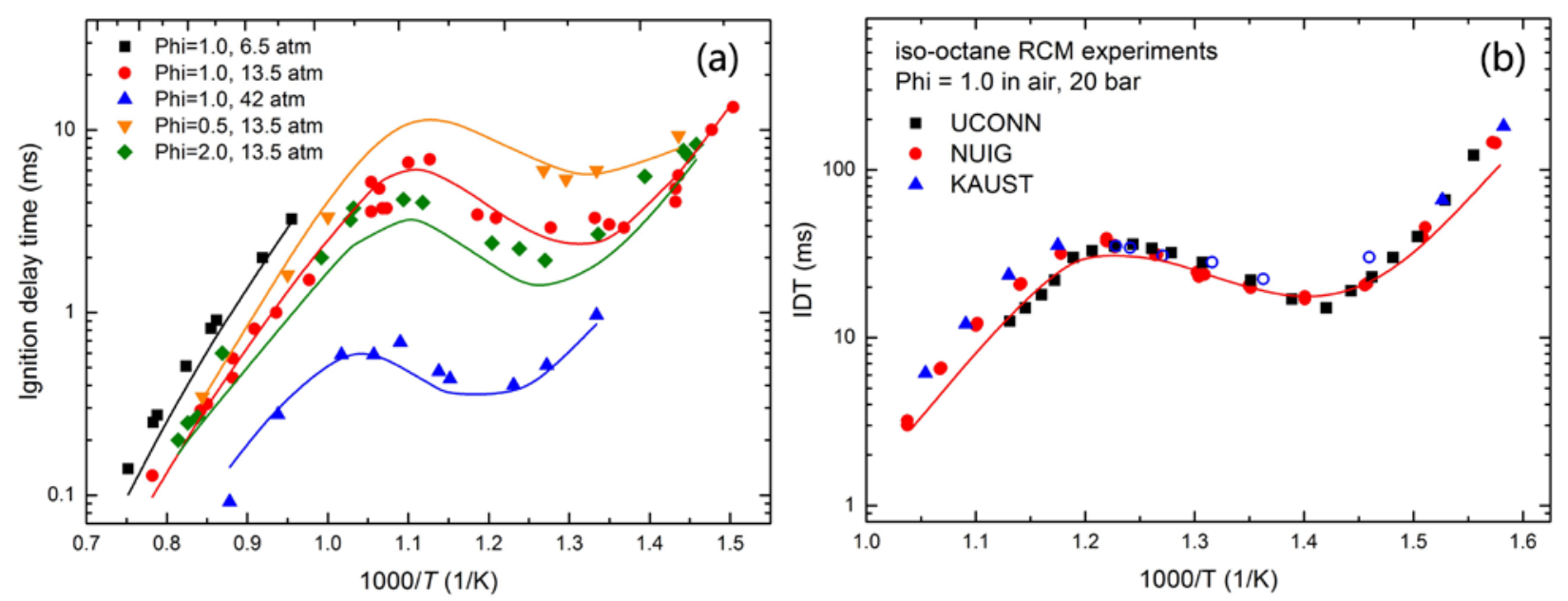

Fig. 10. Validation of updated kinetic models of (a) $n$-heptane and (b) iso-octane using experimental IDT data measured in (a) a shock tube [43] and (b) an RCM [16].

The kinetic model discussed here for the hexane isomers, like all kinetic models, represents a report on current capabilities. Validation tests were carried out by comparing computed results 
with experiments carried out in a shock tube, a rapid compression machine, and a jet-stirred reactor, and each contributes incremental confidence in the positive features of the mechanism. However, as also shown by the validation tests, every model is incomplete and inadequate in many ways and requires continued analysis, corrections, and improvement. Based on the detailed mole fraction comparisons of the JSR data, this model appears to need refinement of the intermediate species sub-models of species including the larger aldehyde and cyclic ether production and consumption. Further refinements of the low temperature alkyperoxy radical isomerization sequence of reactions are needed, since these sub-mechanisms are still not thoroughly understood and quantified.

It is important to understand the kinetic implications of the families of chain reactions in the low temperature portions of the present mechanisms, and they can be stated for the present example of the hexane isomers exactly as they could be stated for any other hydrocarbon fuel that possesses a low temperature kinetic mechanism. As noted above, most of the low temperature kinetic mechanism is divided into classes of reactions, such as Concerted Elimination (i.e., $\mathrm{R}+\mathrm{O}_{2}=$ olefin $+\mathrm{HO}_{2}$ or $\mathrm{RO}_{2}=$ olefin $+\mathrm{HO}_{2}$ ) which provide chain propagation, Cyclization of Hydroperoxyalkyl Radicals (i.e., $\mathrm{QOOH}=\mathrm{Cyclic}$ Ether $+\mathrm{OH}$ or $\mathrm{O}_{2} \mathrm{QOOH}=\mathrm{OOHCyclic}$ Ether $+\mathrm{OH}$ ) which provide chain branching, cyclization to produce ketohydroperoxide species which provide degenerate chain branching, and others. Each of these classes has been studied systematically via theoretical techniques by respected scientists and careful research that in most cases represents the best available approaches, most of them cited above. But few of these classes of low temperature reactions have received very much or any direct experimental attention, with good reasons, usually 
the difficulty of relevant reaction conditions of temperature, pressure, intermediate species lifetimes, or access to the reaction zone. Many of the chemical species involved in these low temperature reaction classes have never even been observed in the laboratory until very recently [47] or at all. Some of these reaction classes have been studied theoretically by different authors and their recommended rates of the same reactions are often quite different. Therefore, there are few examples of low temperature reaction classes where the specific reaction rates are confidently and accurately known. The second piece of these puzzles is that each class of reactions has, on average, a systematic influence on overall rates of low temperature oxidation rates. Thus, concerted elimination reactions generally slow the overall fuel oxidation rate by producing less reactive $\mathrm{HO}_{2}$ radicals, while cyclization reaction classes produce $\mathrm{OH}$ radicals and can accelerate the overall rate of oxidation. As a result, computed ignition delay times can be increased by increasing the rates of concerted elimination reactions and then decreased by increasing the rate of cyclization reactions, so the resulting ignition delay time could be unchanged overall. This can be extended to every class of low temperature reactions. In situations where two or more reaction classes are modified but the overall ignition delay remain unchanged, other intermediate families of intermediate chemical species are sometimes changed, but even then, it is often difficult to measure those differences. The limits of such variability can clearly be refined with guidance from theory or experiments, but this issue remains a challenge to kinetic modelling of low temperature hydrocarbon kinetics.

All of these refinements strongly suggest the need for further experimental studies, 
particularly those like the Wang et al. JSR experiments [6] which provide species-specific data over a range of temperatures and values of the fuel/oxidizer equivalence ratio. Continued refinement of theoretical analyses can also be expected to contribute improved accuracy of important rate parameters. At the same time, the fact that most low temperature kinetics reaction pathways involve chemical species with many heavy atoms and challenge current highperformance computing capabilities.

Of course, the present study of variability of combustion rates with molecular structure addresses only one of many key factors that kinetic models must describe, specifically for stoichiometric fuel/air mixtures of alkane isomers with six C atoms, so further systematic studies with larger alkane fuels, with olefins and other structural classes of hydrocarbons, and with many other operating parameters remain comparatively less studied and are very likely to reward systematic examination. For example, the present study makes no attempt to examine hexanes or other fuels under pyrolysis conditions. Even new studies of the same isomers of hexane at operating conditions the same as and different from the current problems would advance current understanding and refine the conclusions of the present work. Further studies of hexanes and other fuels in other types of experiments, such as flow reactors, laminar premixed and non-premixed flames in various geometries, and other common facilities could provide valuable material for further kinetic mechanism development and validation. Even additional experimental studies of autoignition of fuel-rich and fuel-lean hexane isomers in an RCM, shock tube, and JSR could be extremely instructive and might require an extended revision of the present kinetic mechanisms. 


\section{Conclusions}

Ignition delay times for the straight-chain $n$-hexane and four branched-chain hexane isomers, 2-methylpentane, 3-methylpentane, 2,2-dimethylbutane and 2,3-dimethylbutane were measured in a HPST and in an RCM at NUIG at $\varphi=1, p=15$ bar and $X_{\mathrm{O} 2}=21 \%$ over the temperature range of $600-1300 \mathrm{~K}$. These IDTs of all five hexane isomers, as well as recently published jet-stirred reactor experimental measurements of mole fractions of chemical species produced during oxidation of the same hexane isomers by Wang et al. [6], show correlations between reactivity and fuel molecule structure over a wide range of experiments and reaction temperatures. The most reactive isomer is $n$-hexane, followed by 2- and 3-methylpentane, which have very similar reactivities, followed by 2,2-dimethylbutane, with 2,3-dimethylbutane being the least reactive isomer. Similar trends were also observed for first-stage IDTs at low temperatures, while the reactivities of all five isomers are very similar at high temperatures.

Detailed kinetic mechanisms were developed for all five isomers using unified reaction rate rules. Model predictions show good agreement with experimentally measured first- and secondstage measured IDTs, as well as the trends in their mole fraction levels measured in the JSR experiments, over the entire temperature range, suggesting that the reaction rate rules can well reflect correlations between fuel molecule structure and reactivity under the conditions investigated. Sensitivity analyses have revealed the reaction pathways that are critical in promoting (and inhibiting) reactivity of the fuel and highlight the impact of molecule structure upon oxidation. The reaction rate rules were also implemented and tested for $n$-heptane and iso-octane oxidation 
models. Good agreement was observed from using the updated models, suggesting it is possible to use unified reaction rate rules for kinetic model development of larger alkanes, as well as predicting the correlation between alkane-fuel molecule structure and reactivity through detailed kinetic models.

\section{Acknowledgements}

The work by authors at LLNL was performed under the auspices of the U.S. Department of Energy (DOE), Contract DE-AC52-07NA27344 and was conducted as part of the CoOptimization of Fuels \& Engines (Co-Optima) project sponsored by the DOE Office of Energy Efficiency and Renewable Energy (EERE), Bioenergy Technologies and Vehicle Technologies Offices. The research at NUIG received funding from the People Programme (Marie Curie Actions) of the European Union's Seventh Framework Programme FP7/2007-2013/ under REA grant agreement no 607214 . 


\section{List of Supplementary Material}

1. The full kinetic mechanism and thermodynamic data used in this work with a comprehensive species glossary.

2. Experimental data of and input files for RCM ignition delay time simulations which contain effective volume histories. 


\section{References}

[1] R.D. Reitz, G. Duraisamy, Prog. Energy Combust. Sci. 46 (2015) 12-71.

[2] D. Healy, N.S. Donato, C.J. Aul, E.L. Petersen, C.M. Zinner, G. Bourque, H.J. Curran, Combust. Flame 157 (8) (2010) 1526-1539.

[3] D. Healy, N.S. Donato, C.J. Aul, E.L. Petersen, C.M. Zinner, G. Bourque, H.J. Curran, Combust. Flame 157 (8) (2010) 1540-1551.

[4] M. Ribaucour, R. Minetti, L.R. Sochet, H.J. Curran, W.J. Pitz, C.K. Westbrook, Proc. Combust. Inst. 28 (2) (2000) 1671-1678.

[5] J. Bugler, K.P. Somers, E.J. Silke, H.J. Curran, J. Phys. Chem. A 119 (28) (2015) 75107527.

[6] Z. Wang, O. Herbinet, Z. Cheng, B. Husson, R. Fournet, F. Qi, F. Battin-Leclerc, J. Phys. Chem. A 118 (30) (2014) 5573-5594.

[7] F. Qi, Proc. Combust. Inst. 34 (1) (2013) 33-63.

[8] E.J. Silke, H.J. Curran, J.M. Simmie, Proc. Combust. Inst. 30 (2) (2005) 2639-2647.

[9] K. Zhang, C. Banyon, J. Bugler, H.J. Curran, A. Rodriguez, O. Herbinet, F. Battin-Leclerc, C. B'Chir, K.A. Heufer, Combust. Flame 172 (2016) 116-135.

[10] K. Zhang, C. Banyon, C. Togbé, P. Dagaut, J. Bugler, H.J. Curran, Combust. Flame 162 (11) (2015) 4194-4207.

[11] C.K. Westbrook, W.J. Pitz, J.E. Boercker, H.J. Curran, J.F. Griffiths, C. Mohamed, M. Ribaucour, Proc. Combust. Inst. 29 (1) (2002) 1311-1318.

[12] C.K. Westbrook, W.J. Pitz, H.C. Curran, J. Boercker, E. Kunrath, E., Int. J. Chem. Kinetics 33, (2001) 868-877.

[13] J.M. Smith, J.M. Simmie, H.J. Curran, Int. J. Chem. Kinetics 37 (2005) 728-736.

[14] H.J. Curran, P. Gaffuri, W.J. Pitz, C.K. Westbrook, Combust. Flame 114 (1998) 149-177.

[15] J. Guzman, G. Kukkadapu, K. Brezinsky, C.K. Westbrook, Combust. Flame 201 (2019) 57-64 .

[16] N. Atef, G. Kukkadapu, S.Y. Mohamed, M.A. Rashidi, C. Banyon, M. Mehl, K.A. Heufer, 
E.F. Nasir, A. Alfazazi, A.K. Das, C.K. Westbrook, W.J. Pitz, T. Lu, A. Farooq, C.-J. Sung, H.J. Curran, S.M. Sarathy, Combust. Flame 178 (2017) 111-134.

[17] H.J. Curran, P. Gaffuri, W.J. Pitz, C.K. Westbrook, Combust. Flame 129 (2002) 253-280.

[18] S. Li, S.M. Sarathy, D.F. Davidson, R.K. Hanson, C.K. Westbrook, Combust. Flame 162 (2015) 2296-2306.

[19] S.M. Sarathy, U. Niemann, C. Yeung, R. Gehmlich, C.K.Westbrook, M. Plomer, Z. Luo, M. Mehl, W.J. Pitz, K. Seshadri, M.J. Thomson, T. Lu, Proc. Combust. Inst. 34 (2013) 1015-1023 .

[20] C. Ji, S.M. Sarathy, P.S. Veloo, C.K. Westbrook, F.N. Egolfopoulos, Combust. Flame 159 (2012) 1426-1436.

[21] S.M. Sarathy, C.K. Westbrook, M. Mehl, W.J. Pitz, C. Togbe, P. Dagaut, H. Wang, M.A. Oehlschlaeger, U. Niemann, K. Seshadri, P.S. Veloo, F.N. Egolfopoulos, T. Lu, Combust. Flame 158 (2011) 2338-2357.

[22] M.A. Oehlschlaeger, J. Steinberg, C.K. Westbrook, W.J. Pitz, Combust. Flame 156, 2165-2172 (2009).

[23] Y. Li, C.-W. Zhou, K.P. Somers, K. Zhang, H.J. Curran, Proc. Combust. Inst. 36 (1) (2017) 403-411.

[24] E.R. Ritter, J.W. Bozzelli, Int. J. Chem. Kinet. 23 (9) (1991) 767-778.

[25] S.W. Benson, Thermochemical Kinetics, 2nd ed., Wiley: New York, 1976.

[26] S.M. Burke, J.M. Simmie, H.J. Curran, J. Phys. Chem. Ref. Data 44 (1) (2015) 013101.

[27] Y. Li, H.J. Curran, J. Phys. Chem. A 122 (20) (2018) 4736-4749.

[28] R. Sivaramakrishnan, J.V. Michael, J. Phys. Chem. A 113 (17) (2009) 5047-5060.

[29] A. Miyoshi, Int. J. Chem. Kinet. 44 (1) (2012) 59-74.

[30] S. Sharma, S. Raman, W.H. Green, J. Phys. Chem. A 114 (18) (2010) 5689-5701.

[31] S.M. Villano, L.K. Huynh, H.-H. Carstensen, A.M. Dean, J. Phys. Chem. A 115 (46) (2011) 13425-13442.

[32] S.M. Villano, L.K. Huynh, H.-H. Carstensen, A.M. Dean, J. Phys. Chem. A 116 (21) (2012) 
5068-5089.

[33] Z. Wang, L. Zhang, K. Moshanner, D.M. Popolan-Vaida, V.S.B. Shanker, A. Lucassan, C. Hemken, C.A. Tastjes, S.R. Leone, K. Kohse-Hoinghaus, N. Hansen, P. Dagaut, S.M. Sarathy, Combust. Flame 164 (2016) 386-396.

[34] Z. Wang, S.M. Sarathy, Combust. Flame 165 (2016) 364-372.

[35] CHEMKIN-PRO, Release 19.2, ANSYS, Inc., Canonsburg, PA, 2018.

[36] C.-J. Sung, H.J. Curran, Prog. Energy Combust. Sci. 44 (Supplement C) (2014) 1-18.

[37] W. G. Lovell, Industrial and Engineering Chemistry 40 (1948) 2388-2438.

[38] C.K. Westbrook, M. Sjoberg, N.P. Cernansky, Combust. Flame 195 (2018) 50-62 .

[39] C.K. Westbrook, W.J. Pitz, O. Herbinet, H.J. Curran, E.J. Silke, Combust. Flame 156 (2009) 181-199.

[40] C.K. Westbroook, Proc. Combust. Inst. 28 (2000) 1563-1577.

[41] J. Moriarty, H. Sidebottom, J. Wenger, A. Mellouki, G.L. Bras, J. Phys. Chem. A 107 (10) (2003) 1499-1505.

[42] H.K. Chakravarty, R.X. Fernandes, J. Phys. Chem. A 117 (24) (2013) 5028-5041.

[43] H. Ciezki, G. Adomeit, Combust. Flame 93 (1993) 421-433.

[44] M. Mehl, W.J. Pitz, C.K. Westbrook, H.J. Curran, Proc. Combust. Inst. 33 (2011) 193-200 .

[45] M.F. Campbell, S. Wang, D.F. Davidson, R.K. Hanson, Combust. Flame 185 (2018) 376392.

[46] Z.E. Loparo, J.G. Lopez, S. Neupane, W.P. Partridge, Jr., K. Vodopyanov, S.S. Vasu, Combust. Flame 185 (2017) 220-233.

[47] J.D. Savee, E. Papajak, B. Rotavera, H. Huang, A.J. Eskola, O. Welz, L. Sheps, C.A. Taatjes, J. Zador, D.L. Osborn, Science 347 (2015) (6222) 643-645. 
This document was prepared as an account of work sponsored by an agency of the United States government. Neither the United States government nor Lawrence Livermore National Security, LLC, nor any of their employees makes any warranty, expressed or implied, or assumes any legal liability or responsibility for the accuracy, completeness, or usefulness of any information, apparatus, product, or process disclosed, or represents that its use would not infringe privately owned rights. Reference herein to any specific commercial product, process, or service by trade name, trademark, manufacturer, or otherwise does not necessarily constitute or imply its endorsement, recommendation, or favoring by the United States government or Lawrence Livermore National Security, LLC. The views and opinions of authors expressed herein do not necessarily state or reflect those of the United States government or Lawrence Livermore National Security, LLC, and shall not be used for advertising or product endorsement purposes. 